ISSN No. 2454 - 1427

CDE

November 2017

\title{
Takings of Land by Self-interested Governments Economic Analysis of Eminent Domain
}

\author{
Hans-Bernd Schäfer \\ Bucerius Law School, Hamburg
}

Ram Singh

Email: ramsingh@econdse.org

Department of Economics

Delhi School of Economics

\section{Working Paper No. 281}

http://www.cdedse.org/pdf/work281.pdf

\section{CENTRE FOR DEVELOPMENT ECONOMICS}

DELHI SCHOOL OF ECONOMICS

DELHI 110007 


\title{
Takings of Land by Self-interested Governments Economic Analysis of Eminent Domain
}

\author{
Hans-Bernd Schäfer*and Ram Singh ${ }^{\dagger} \ddagger$
}

\begin{abstract}
In this paper, we model and examine the effects of two salient features of the eminent domain law and its use. First, the compensation is less than 'full'. Second, the government is not a perfect agent of the society. Once these features are factored in, several claims in the existing literature do not hold. Our results question the 'fiscal-illusion' theory. We show that the full compensation ensures efficiency neither of the takings nor of the investment decisions. Moreover, things can get worse with tightening of the budget constraints. However, under-compensation combined with the provision of restitution delivers a better outcome - in terms of investment choices by the owners as well as the taking decisions and project choices by the government. Further, we show that fixed-compensation schemes generally are not efficient even if the government is benevolent, but under-compensation can still deliver outcome more efficient than the full compensation.
\end{abstract}

\section{Introduction}

The private right over property vis-à-vis the state has been a matter of intense debate across societies and times. In jurisdictions influenced by Roman law, property together with land is seen as an absolute right to be protected from everybody including the state. Therefore, the state is allowed to take away property only for the sake of social welfare. Drawing on this perspective, today many 'civil law' based

\footnotetext{
*Professor of Law and Economics, Bucerius Law School, Hamburg. Email: hansbernd.schaefer@law-school.de.

${ }^{\dagger}$ Professor of Economics, Delhi School of Economics, University of Delhi, Delhi, INDIA 110007. Email: ramsingh@econdse.org

${ }^{\ddagger}$ We thank Hans-Peter Bull, Michael Fehling, Parikshit Ghosh, Wolfgang Hoffmann-Riem and Hans-Joachim, Ilya Somin, Urs Schweizer and Juergen Eichberger for valuable comments and suggestions.
} 
legal orders including the members of the Council of Europe regard land property not only as an absolute right but as a fundamental human right. ${ }^{1}$

On the other hand, in jurisdictions based on tribal legal traditions like the common law countries, private property was originally considered a privilege to be given and withdrawn by the ruler as circumstances required. In these countries, even today the power of the state to take away property remains dominant, though subject to the legal restrictions.

The difference in the two legal traditions is amply reflected in the language used to describe the expropriation power of the state; namely, 'eminent domain'2 in the common law countries, and 'taking' (away) or expropriation in the civil law countries. ${ }^{3}$

Nonetheless, the actual practice of expropriation of property by the state has remained a matter of fierce debate in many countries. Even in the countries with a strong rule of law, criticisms are rampant about unjustified takings as well the quantum of compensation. The situation is much worse in countries with a legal orders that do not provide strong protection to property, or where the enforcement is weak. See Glaeser et al. (2016), Somin (2015) and Singh (2012).

Given the importance of the subject it is not surprising that a large literature has come up on the economic analysis of the taking law. Some of the notable contributions are Blume and Rubinfeld (1984), Miceli (1991, 2008, 2011); Miceli and Segerson (2012), Hermalin (1995), Innes (2000), Claeys (2003), Tideman and Plassmann (2005), Nosal (2001), Epstein (2008, 2012), Göller and Hewer (2014), and Schweizer (2017). ${ }^{4}$

However, most of these works do not pay adequate attention to the following important features of the takings law and its use. One, compensation for takings under eminent domain is systematically less than the 'full' compensation as under-

\footnotetext{
${ }^{1}$ See Human Rights Handbook (No.10)

${ }^{2}$ The term comes from medieval Latin "dominium eminens" meaning "supreme lordship".

${ }^{3}$ The legal literature on the subject is insightful. For instance, prior to independence of the US, in the New England states the taking of land by the state was easy and compensation was not paid. While the crown officials justified uncompensated takings by appealing to the royal prerogative and limitations contained in the original land grants, such redistributions were legitimized by a powerful strand of English legal thought with its origins in the feudal notions of property and kingship. (See (Treanor, 1985, p.695)). On the contrary, under classical Roman law, as a rule the transfer of land was done with the approval of the owners. Herber (2015) writes this about public construction work in the Roman Empire: "The state acquires the necessary area for the realization of the planned road. The expropriation as coercive measure of the state is the "ultima ratio" only after intensive efforts to acquire the land" (p.5)

${ }^{4}$ Also see Michelman (1967), Blume et al. (1984), Niemann and Shapiro (2008), Posner (2014), and Burrows (1991), Fischel and Shapiro (1989), Trefzger and Colwell (1996) and Miceli and Segerson (1994)
} 
stood in the context of civil liability cases. Two, monetary considerations do not apply to the decision making of the government and its agencies in the same way as they do for the private actors. Three, most legal jurisdictions give the affected owners a choice between accepting the takings with compensation, or challenging it to seek an action for the restitution of the properties in an administrative or constitutional court. Four, the 'third-party effects' of takings can be significant. In the existing literature, these effects are often ignored. It is generally assumed that all important effects of a taking decision are contained in the relation between the state and the affected owners. However, in many real-world contexts, some of the important adverse effects stretch to third parties, including the public at large.

In this paper, we allow the probability of taking to depend on investments made by property owners. However, we draw upon the public choice literature to argue that the civil liability approach cannot be used to model and examine the behaviour of state actors. Moreover, the real-world governments pursue their own interests, which are not necessarily the same as the social interests. Once these features of the real-word governments are factored in, several claims in the existing literature on eminent domain do not hold.

We show that when compensation is full, neither the taking decision nor the project choice by the government will be efficient. On top of it, there will be excessive investments by property owners. However, if under-compensation (less-than-full compensation) is combined with the provision of restitution, ${ }^{5}$ the outcome is better than the outcome under full compensation on the following three counts: One, investment levels are more efficient; two, a taking happens only if it contributes to the social welfare; three, the project choice by the government is also better. Therefore, less-than-full compensation not only serves as a safeguard against misuse of the eminent domain power by the state, it is good from efficiency point of view as well.

Moreover, we shows that the under-compensation combined with restitution dominate the full compensation, even when the government is benevolent. However, if the taking is for a 'private' investor, full compensation to the affected parties can be a reasonable approach for an efficient use of the eminent domain. Similarly, there can be a case for full compensation if the action for restitution is not available or is simply ineffective.

Besides, we question the 'fiscal illusion' based theory of government's behavior. Contrary to the conventional understanding, we show that a tightening of the budget constraint can guarantee neither a higher number nor an increased quota of socially

\footnotetext{
${ }^{5}$ This provision enables the owners to approach a court to seek restitution of the property when the taking is unlawful, and an injunction against a proposed unlawful taking. See Section 5 for details.
} 
desirable projects.

Our findings have direct implications for several claims in the existing literature. The leading works assume that the probability of taking is independent of the investment choices of the land owners or that the government is benevolent, or both. ${ }^{6}$ Under these assumptions, the literature claims that full compensation can solve the problem of moral hazard on part of the government. ${ }^{7}$ Moreover, when taking decision does not depend on investment levels, full compensation can achieve efficiency of the takings as well as investment decisions. ${ }^{8}$ Further, when the taking decision depends on investment levels, fixed-compensation can ensure an efficient outcome. ${ }^{9}$ In contrast to these claims, we show that when the government is not benevolent, full compensation cannot guarantee social efficiency of taking decisions; problem of moral hazard on part of the government persists. Moreover, none of the standard compensation schemes, including zero and fixed compensation is efficient.

Our results are also relevant for the recent works on the subject. For instance Schweizer (2017) models a situation in which the government's preference deviate from the social preference, on account of social-choice constellation. He proposes a civil liability based mechanism to achieve the first best solution. Besides, his mechanism requires payment for all third-party effects, but to a separate and disinterested entity. ${ }^{10}$ Similarly, Göller and Hewer (2014) provide a mechanism to achieve the first best. However, these mechanisms assume that there is only property owner and are based on the civil liability approach, which is disputed in this paper.

In Section 2, we proceed by first showing that government takings lead to damage awards lower than under civil liability, a finding important for the analysis of the action for restitution. In Section 3, we present the model consisting of the state and several private investors whose property might or might not be taken. In this section, we present the first best solution, in which the decisions on takings, project

\footnotetext{
${ }^{6}$ See Blume and Rubinfeld (1984), Epstein (1985, 1995, 2008), Burrows (1991), Miceli (1991), Giammarino and Nosal (2005), Farber (1992), Fischel (1995), Yandle (1995), Fischel and Shapiro (2011), Hermalin (1995) and others. Munch (1976), Brennan and Boyd (2006), Pecorino (2011, 2013), and Miceli and Segerson (1994) also present a similar analysis.

${ }^{7}$ (Epstein, 1985, 1995, chapter 5), Burrows (1991), Farber (1992), Fischel (1995), Innes (1997), Kaplow (1986), and Yandle (1995) argue that full compensation solves the moral hazard problem.

${ }^{8}$ See Hermalin (1995) and Miceli (2011), among others. Full compensation has been justified on some other grounds as well. See Brennan and Boyd (2006), Pecorino (2011, 2013) and Miceli and Segerson (1994).

${ }^{9}$ In Blume and Rubinfeld (1984), Blume et al. (1984), Kaplow (1986, 1992) and Giammarino and Nosal (2005) compensation fixed at zero leads to an efficient outcome, under the assumption that the probability of taking is independent of the investment decision. Miceli (1991); Miceli et al. (2007), Trefzger and Colwell (1996) and Göller and Hewer (2014) assume that the likelihood of a taking depends on the value of the property, and require the compensation to be positive.

${ }^{10}$ For a critique of Schweizer (2017), see Klerman (2017).
} 
choice and investment levels are taken to maximize the social gains. In Section 4, we model the decision making of self-interested governments. Section 5 examines the outcome and its properties, when the government is self-interested but there is legal provision that enables owners to seek restitution of land. Here, we consider the case of full compensation as well as the case of less-than-full compensation. In Section 6 , we move in line with existing literature and assume a benevolent government. In Section 7, we discuss the implication of budget constraint on the efficiency of the taking decisions. Section 8 discusses the private purpose takings and Section 9 concludes the analysis in the paper.

\section{Compensation for taking is less than full}

Here we show that compensation for takings is less than full. Specifically, it is less than what is understood as full compensation under a civil liability claims. ${ }^{11}$ This observation is crucial for further analysis. What is 'full' compensation? Consider an individual who is faced with a loss of property and the resultant loss of utility. The full compensation would require providing the individual with the amount of money or assets or goods such that she is back to the original utility level. An equivalent definition of full compensation is a sum leading to the willingness to accept the taking ${ }^{12}$.

Many legal orders including Germany conceptualize the full compensation under civil liability using some version of what is called the 'differential method' (Sabahi and Birch, 2010). Under this method, a court compares the actual wealth of the claimant consequent to the wrongful act with her hypothetical wealth assuming the wrongful act had not occurred. The difference between the two is used to compute compensation so as to restore the claimant to the utility level in the absence of the wrongful act. This way of assessing the damage will factor in all relevant variables. Depending of the context, it can include future expectations, loss of the good will, interest, losses from currency devaluation, and any other loss of wealth, and obligations arising on account of an interference of the wrongful act with an existing contract. ${ }^{13}$

In contrast to the civil liability, under the law of eminent domain a precise formula such as the differential method does not exist. Instead one encounters

\footnotetext{
${ }^{11}$ Discussion in this section draws upon Schäfer (2017). Also see Sabahi and Birch (2010).

${ }^{12}$ See Chang (2013).

${ }^{13}$ However in many countries including Germany the use of this method does not include nonpecuniary losses like sentimental value, mental stress or reduced quality of life. The method then arrives not at the restoration of utility but of wealth. Some countries like France and Spain include such damages in civil liability too and come even closer to the economic concept of a damage. (Winiger, Koziol, Koch, Zimmermann 2011, 752).
} 
different vague terms, which have to be substantiated by the relevant jurisdiction. This is true of the national laws as well as the international law. However, almost all of these terms have one thing in common. In practice, they invariably lead to a damage award less than the level of compensation according to the differential method frequently used in tort law cases. To corroborate this claim, below we briefly discuss the international (investment) law and cite examples from some leading national constitutional laws.

In international contexts, the damage award depends on whether the use of the eminent domain power against a foreign investor is legal under the international law or not. ${ }^{14}$ In case of the former, different formulas are used to assess damage awards. However, the frequently used method is the 'Hull formula', which requires a 'prompt, adequate and effective' compensation, which means that the compensation should be without unreasonable delay, cover the fair market value and should be transferable. Under this method the compensation amounts to a damage award lower than under the differential method. As such the term 'fair market value' is subject to legal dispute since it could be viewed at as the actual market value, the discounted future income stream or the book value. Otherwise also, in many ways the market value can fall short of the full compensation according to the difference principle. Since, it does not necessarily include damages on account of the sunk expenses like advertising or training, losses resulting from a relocation of the business. Similarly, the market value might not include losses that will arise if the taking cuts into an existing contracts between the affected and the third parties.

It is only when the act of expropriation violates an international law that the damage award might be based on the differential method. An example is a government taking of a foreign company in violation of a bilateral investment treaty or international customary law (Sabahi and Birch, 2010) ${ }^{15}$. Otherwise, the current practice of the Hull formula leads to an award lower than under the differential method, even though it can be higher than according to some other infrequently used formulas.

Moreover, a UN resolution on the "New International Economic Order", provides for "just compensation" as guiding principle for a damage award under the international law, which can allow the government to take into account instances of colonialism while calculating damages and thus potentially reduce the award to a nominal compensation. Consequently, compensation can even be less than what will follow according to the Hull formula. In national laws one finds no compensa-

\footnotetext{
${ }^{14}$ See Niemann and Shapiro (2010)

${ }^{15}$ (Sabahi and Birch, 2010) cites the case of a group of Irish farmers in Zimbabwe, whose farms were expropriated. This was regarded as a violation of international law. The ICSID calculated a damage award according to the differential method. For a detailed discussion on international issues, see Kim, Lee and Somin (2017).
} 
tion rule with the precision and comprehensiveness of the differential method either. Under the Constitution of the United States of America (Fifth Amendment), the use of eminent domain power must lead to "just compensation", which in practice means market value compensation. Use of standards all of which differ from the differential method can also be found in the law of other countries. For instance, in India where private property is not a fundamental constitutional right, the land acquisition law uses the term 'fair compensation'. ${ }^{16}$ The constitution of the Republic of Korea also refers to the term "just compensation" (Art.23, 3). The Chilean Constitution (Art. 24) requires only "compensation in cash". The constitution of the Republic of China (Taiwan) protects private property as a right (Art. 15 and 23), but remains silent on a compensation formula for taking, implying that parliament is free to define the formula in sub-constitutional law. ${ }^{17}$ In Germany compensation for expropriation is governed by the Article 14 (3) of the constitution along with the sub-constitutional laws at the state level. The constitution does not require full compensation but a compensation, which balances interests of the society with those of the affected individuals. The constitution allows the sub-constitutional legislator to fix a damage compensation below a civil liability award. ${ }^{18}$ The constitution rules out a purely nominal compensation. It allows but does not require full damage compensation. (Pieroth et al. 2014). Usually the compensation is the market value, but if circumstances require less than the market value may be paid (under the 'Reduction clauses').

There is a doctrinal rationale for the less than full compensation under the eminent domain law. Unlike a civil liability award which aims to compensate the consequences of an unlawful tortuous act, a constitutional taking is lawful and in the interests of the public. This means that the affected citizens may have to make some contribution for the pursuance of the common good for which the taking decision was made. It may also require that the damage award is further reduced if the citizen not only loses property but also stands to gain from the taking decision; for instance, when the state provides an agricultural hinterland with roads and electricity.

One can give more examples from national laws to show that usually under the national and international laws compensation is either the market value of the taken land or even less. ${ }^{19}$ Overall lawful takings systematically entail compensation less than a damage award according to the differential method used in civil liability

\footnotetext{
${ }^{16}$ It is obvious from the very title of Act, which is 'The Right to Fair compensation and Transparency in Land Acquisition, Rehabilitation and Resettlement Act, 2013'.

${ }^{17}$ For further discussion see Chang (2017)

${ }^{18}$ Such compensation shall be determined by establishing an equitable balance between the public interest and the interests of those affected. Art. 14 (3), Basic Law of the Federal Republic.

${ }^{19}$ See Rachelle Alterman et al(2010) for a detailed discussion on property rights of different countries around the world.
} 
claims. In the following sections, we will examine the incentive effects of this feature of compensation for taking.

\section{Basics of the Model}

\subsection{Eminent Domain Context}

Consider a collection of many contiguous parcels of land located in a neighborhood and owned by private persons. For simplicity assume that properties are homogeneous and of the same size. Different parcels are owned by different legal persons or individuals. The neighborhood might become the target of expropriation by the state under eminent domain law, for a public or a private investment project. The former includes uses for the provision all state services like public goods, transportation networks, hospitals, schools, universities or sports grounds, for which the law allows the use of eminent domain power. The latter includes private investment projects of profit oriented private investors. If the state uses the eminent domain power, all of the land parcels of the neighborhood will be needed. These assumptions are made in the interest of simplicity. However, they guarantee a hold up by the owners, which makes it difficult or impossible for the state or a private investor to realize new investment projects in the neighborhood by purchasing all pieces of land through voluntary transactions. Hold out is considered to be a necessary condition for economic justification of using the eminent domain power. ${ }^{20}$ Moreover, we assume that the owners, project developers and the Government are all risk-neutral. ${ }^{21}$

As each person owns one piece of land, we can use the same index, $i$, for an individual and her property; $i=1, \ldots, I$. A land-owner can invest in her property. ${ }^{22}$

The investment increases the value of the land to the owner. Let,

$v_{i}$ denote the value of the property to its owner $i$.

$v_{i}$ is a function of the investment level, $x_{i}$, made by the owner $i ; v_{i}=v_{i}\left(x_{i}\right)$ such that $v_{i}^{\prime}\left(x_{i}\right)>0, v_{i}^{\prime \prime}\left(x_{i}\right)<0$. To keep things simple, let the payoff function $v\left(x_{i}\right)$ be

\footnotetext{
${ }^{20}$ For a general discussion see Cohen (1991), Posner (2003). For a more detailed analysis see Strange (1995), Epstein (1985) [Chap. 12], and Shavell (2010). Calabresi and Melamed (1972) informally discusses the problem of strategic hold-out and the consequent need for eminent domain. In some jurisdictions, it also a precondition for any constitutional taking decision. See Bernd Schäfer (2017).

${ }^{21}$ For analysis of takings with risk-averse investors see Blume et al. (1984) and Miceli (1991). Also see Kaplow (1986).

${ }^{22}$ For a setting involving investment by owners and non-owners see Ghatak and Mookherjee (2014).
} 
the same across individuals. That is, $v_{i}\left(x_{i}\right)=v\left(x_{i}\right)$ for all $i=1, \ldots, I$. Moreover, $v(\cdot)$ is increasing and concave, i.e., $v^{\prime}\left(x_{i}\right)>0, v^{\prime \prime}\left(x_{i}\right)<0$ and satisfies Inada type conditions, $\lim _{x_{i} \rightarrow 0} v^{\prime}\left(x_{i}\right)=\infty, \lim _{x_{i} \rightarrow \infty} v^{\prime}\left(x_{i}\right)=0$ for all $i=1, \ldots, I$. Owners choose investment levels at date $t=1$. The government takes a decision about expropriation at date $t=2$. Specifically, at $t=2$ the government decides whether to acquire these properties of the above neighborhood. Note that the decision about the taking is made after the owners have made the investment decisions. ${ }^{23}$ All investments are assumed to be sunk and have no value on secondary markets. One can think of investments such as tube wells, irrigation canals, farmhouses, hedges, fences, farm tracks and stables but not caterpillars or equipment. ${ }^{24}$ Specifically, if the government takes away any property, the owner cannot not enjoy any part of $v\left(x_{i}\right)$. In that case, the entire investment turns out to be a complete waste. Therefore, the taking will entail a direct social cost of $\sum_{i=1}^{I} v\left(x_{i}\right)$.

The expropriated properties can be used for only one new project, which can be for a project for public use or a private investment project. Let,

$$
\mathbb{P}=\{1,2, \ldots, P\}
$$

be the set of potentially feasible alternative projects at date $t=2$. Examples of projects in the set $\mathbb{P}$ could include using the acquired land for developing a publicpark, or a slip road, or a golf-course. However, one and only one of these projects can be taken up.

Let, $\beta_{p}^{S}$ be the social benefit from project $p$, which covers all costs and benefits but not the losses of the landowners; where $p \in \mathbb{P}$.

$\beta_{p}^{S}$ depends on the state of nature, that is the general economic conditions as observable at $t=2$. Let, $\theta$ denote the state of nature. $\theta$ becomes observable to all those concerned at $t=2$ i.e., when the government decides whether to expropriate the properties or not. For instance, one can think of $\theta$ as the growth rate of the economy at $t=2$. A high growth rate can lead to greater appetite for investment by the private sector. Therefore, private investment itself might require the taking of the above properties for a private project such as an industrial complex or a special economic zone. Moreover, the government might want to facilitate private sector investment by providing additional infrastructure and other public goods, which can be provided on the above mentioned neighborhood. From this perspective, the social

\footnotetext{
${ }^{23}$ These assumptions are line with much of the literature (Blume et al. (1984), Miceli (1991), Göller and Hewer (2014) and Schweizer (2017)).

${ }^{24}$ For non-specific investments see Porat (2017).
} 
benefits of projects from taking is expected to increase with the observed growth rate at $t=2$. In general, $\theta$ denotes the state of nature relevant for the social value of the project, i.e., $\beta_{p}^{S}=\beta_{p}^{S}(\theta)$. We assume that the social benefit is bounded above, i.e., there exists some $K>0$ such that, $\beta_{p}^{S}(\theta)<K$ for all $p \in \mathbb{P}$ and all $\theta \in \Theta$.

At $t=1$, i.e., when the owners decide on the investment levels, there is uncertainty about $\theta$. Formally, at $t=1, \theta$ is a random variable. Assume $\theta \in[\underline{\theta}, \bar{\theta}]$, where $\underline{\theta}<\bar{\theta}$. Let $F(\theta)$ and $f(\theta)$, respectively, be its distribution and density functions. ${ }^{25}$

To determine the net social gain from project $p$, from the gross social value $\beta_{p}^{S}(\theta)$ of the project the forgone gain of all owners whose land was condemned must be deducted, as by assumption it is completely lost after the taking. This foregone gain is a function of the investment, $x_{1}, \ldots, x_{I}$, made by the owners at $t=1$. Let $\mathbf{x}=\left(x_{1}, \ldots, x_{I}\right)$. For given $\theta$ and $\mathbf{x}$, let

$\pi_{p}^{S}(\theta, \mathbf{x})$ denotes the net social gains from project $p \in \mathbb{P}$.

Clearly,

$$
\pi_{p}^{S}(\theta, \mathbf{x})=\beta_{p}^{S}(\theta)-\sum_{i=1}^{I} v\left(x_{i}\right)
$$

Remember that $\mathbb{P}$ is the collection of potential alternative projects that can be taken up in the neighborhood, but only one project will be realized in case of the taking. From the social efficiency perspective, a project should be realized only if it generates positive net social surplus. The set of projects with positive net social surplus can be defined as:

$$
\mathbb{P}^{S+}(\theta, \mathbf{x})=\left\{p^{\prime} \mid p^{\prime} \in \mathbb{P} \& \pi_{p^{\prime}}^{S}>0\right\}
$$

Depending on the state of nature (the scenario at hand), the number of projects with positive net social surplus can be just one, more than one or zero, i.e., the set $\mathbb{P}^{S+}(\theta, \mathbf{x})$ could be singleton, have more than one element, or a null set. For example, given the investment levels, if the public-park as well as the slip road will generate positive net social gains, then both these projects belong to the set $\mathbb{P}^{S+}(\theta, \mathbf{x})$. In contrast, if the golf-course will not result in the positive net social gains, then it will not belong to the set $\mathbb{P}^{S+}(\theta, \mathbf{x})$.

\footnotetext{
${ }^{25}$ Using the above interpretation of $\theta$, the growth rate will vary across economies and across regions/localities within an economy, leading to different distributions of $\theta$. More generally, $F(\theta)$ and $f(\theta)$, will vary across contexts.
} 
From efficiency perspective, a project should be taken up only if it belongs to the set $\mathbb{P}^{S+}(\theta, \mathbf{x})$. Ideally, the most desirable project in the set $\mathbb{P}^{S+}(\theta, \mathbf{x})$ should be realized. Let

$$
\pi^{S *}(\theta, \mathbf{x})=\max \left\{\pi_{p}^{S}(\theta) \mid p \in \mathbb{P}^{S+}\right\}
$$

That is, given the state of nature $\theta$ and the profile of individual investments $\mathbf{x}$, $\pi^{S *}(\theta, \mathbf{x})$ denotes the maximum possible value of the net social benefit that can be achieved from the takings. In other words, if $\pi^{S *}(\theta)=\pi_{\hat{p}}^{S}(\theta)$, the social gains are highest from the $\hat{p}$ th project. For instance, if $\mathbb{P}^{S+}(\theta, \mathbf{x})=\{$ public-park, slip road $\}$, and the social benefit is higher for the public-park than for the slip road. In that case, $\hat{p}$ stands for the identity of the socially best project, here the public park. Besides, $\pi^{S *}(\theta, \mathbf{x})$ is the social benefit from the public park. Naturally, the socially most efficient project will vary across $\theta \in[\underline{\theta}, \bar{\theta}]$. Without loss of generality, we rule out the possibility of tie by assuming that for any given $\mathbf{x}$ and $\theta$, only one project maximizes the social welfare.

Remember that investments by private owners occurs at $t=1$. At $t=2$, these investments are sunk costs by assumption. If the government does not take away these private properties, total benefit enjoyed by the landowners is equal to $\sum_{i=1}^{I} v\left(x_{i}\right)$. So, at $t=2$, if the taking happens, the opportunity cost will be the total benefits forgone by the landowners, i.e., $\sum_{i=1}^{I} v\left(x_{i}\right)$. This opportunity cost is independent of the choice of project by the government. Therefore, the project with the highest social gross benefit will also be the project with the highest social net benefit, and vice-versa. That is, $\pi_{\hat{p}}^{S}(\theta)=\pi^{S *}(\theta)$ iff $\beta_{\hat{p}}^{S}(\theta)=\beta^{S *}(\theta)$. However, it is not guaranteed that the project with the highest social gross benefit has also a positive social net benefit. Depending on $\theta$ and $\mathbf{x}$, we can have

$$
\pi^{S *}(\theta, \mathbf{x})=\beta^{S *}(\theta)-\sum_{i=1}^{I} v\left(x_{i}\right) \lesseqgtr 0 .
$$

\subsection{The First Best}

Our analysis starts with the first best solution, in which the private landowners and the government are assumed to be perfect agents of the common good while making their decisions. At date $t=1$, the private property owners decide on their investment levels. At date $t=2$, the government observes $\theta$ as well as $\mathbf{x}$ and makes the following two decisions: First, whether to takes the properties; second, if yes for which of the possible projects it wants to realize.

We can find out the socially efficient decisions by backward induction, starting 
with the government's decision at date $t=2$. The taking is socially desirable and should be done if and only if the set of net welfare increasing projects is non-empty, i.e, if and only if the set $\mathbb{P}^{S+}(\theta, \mathbf{x})$ is non-empty. Moreover, project $\hat{p}$ should be realized, if and only if out of the net welfare increasing projects, it increases social welfare the most, i.e., project $\hat{p}$ should be implemented, if and only if $\pi_{\hat{p}}^{S}(\theta, \mathbf{x})=$ $\max \left\{\pi_{p}^{S}(\theta) \mid p \in \mathbb{P}^{S+}\right\}=\pi^{S *}(\theta, \mathbf{x})$. Since at date $t=2, \mathbf{x}$ is given, therefore, the social desirability of the taking decision depends only on the state of nature $\theta$. The properties should be taken if and only if the state of nature $\theta$ is such that $\pi^{S *}(\theta, \mathbf{x})>0$ holds, i.e., iff $\theta \in \Theta^{*}(\mathbf{x})$, where

$$
\Theta^{*}(\mathbf{x})=\left\{\theta \mid \pi^{S *}(\theta, \mathbf{x})>0\right\}
$$

Note that if the state of nature $\theta$ is such that $\pi^{S *}(\theta, \mathbf{x})>0$ holds it means that there exists at least one project with net positive social gains, i.e., the set $\mathbb{P}^{S+}(\theta, \mathbf{x})$ will be non-empty. Alternatively, when the set $\mathbb{P}^{S+}(\theta, \mathbf{x})$ is non-empty, we can always find the project with the highest social surplus. Formally, from (3) and (4) the following holds: For any given $\mathbf{x}$,

$$
\theta \in \Theta^{*}(\mathbf{x}) \Leftrightarrow \mathbb{P}^{S+}(\theta, \mathbf{x}) \neq \emptyset
$$

To keep the analysis meaningful we exclude the possibility that taking is always socially efficient, irrespective of the value of $\theta$ - because that would imply that the probability of taking is 1 . Equally, we exclude the possibility of that the taking is always undesirable, regardless of the state of the nature. Formally, we take that $\Theta^{*}(\mathbf{x})$ and its complement $\widetilde{\Theta}^{*}(\mathbf{x})$ in $[\underline{\theta}, \bar{\theta}]$ are both non-empty.

In the next step we solve for the efficient levels of investment by the owners, assuming that at date $t=2$ the taking is done if and only if the state of nature is such that $\theta \in \Theta^{*}(\mathbf{x})$. At date $t=1$, the state of nature $\theta$ is unknown. However, the distribution function $F(\theta)$ and the density function $f(\theta)$ are known. Moreover, it is known that probability of the taking is: $\operatorname{Prob}\left[\theta \in \Theta^{*}(\mathbf{x})\right]$, for any $\mathbf{x}$.

It is important to notice that the investment levels at $t=1$ affect not only the sunk costs in the event event of the takings, but also the probability of socially efficient takings at $t=2$. As the investment levels go up so does the opportunity cost of the takings. Intuitively, the probability of an efficient taking should decrease as investment levels go up. Indeed, if we assume that $\beta^{S *}(\theta)$ is an increasing function of $\theta$, the probability of an efficient taking can be expressed in terms of the above distribution function, $F(\cdot)$. To this end, consider the following equation: 


$$
\pi^{S *}(\theta, \mathbf{x})=\beta^{S *}(\theta)-\sum_{i=1}^{I} v\left(x_{i}\right)=0 .
$$

For a given profile of individual investments denoted by $\mathbf{x}$, let $\hat{\theta}$ solve (6). Clearly, $\hat{\theta}$ depends on $\mathbf{x}$, i.e., $\hat{\theta}=\hat{\theta}(\mathbf{x})$. This means that if the state of the nature is $\hat{\theta}$, then the net social benefit from the taking is 0 , i.e., $\pi^{S *}(\hat{\theta})=0$. Without loss of generality assume $\frac{\partial \beta^{S *}(\theta)}{\partial \theta}>0 .{ }^{26}$ When $\frac{\partial \beta^{S *}(\theta)}{\partial \theta}>0$, we have $\frac{\partial \pi^{S *}(\theta)}{\partial \theta}>0$. Therefore for all $\theta>\hat{\theta}$, $\pi^{S *}(\theta)>0$, i.e., the taking is socially efficient. The probability that taking is not efficient is simply the probability that $\theta \leq \hat{\theta}(\mathbf{x})$, i.e., $F(\hat{\theta}(\mathbf{x}))$. Therefore, at date $t=1$, socially optimal levels of individual investments should solve: ${ }^{27}$

$$
\max _{x_{1}, x_{2}, \ldots, x_{I}}\left\{F(\hat{\theta}(\mathbf{x})) \sum_{i=1}^{I} v\left(x_{i}\right)+\int_{\hat{\theta}(\mathbf{x})}^{\bar{\theta}} \beta^{S *}(\theta) f(\theta) d \theta-\sum_{i=1}^{I} x_{i}\right\}
$$

Assume that the social benefit function in (7) is concave in $\mathbf{x}$, and the optimization problem has a unique interior solution, say $\left(x_{1}^{*}, x_{2}^{*}, \ldots, x_{I}^{*}\right)$. The first order conditions reduce to the following:

$$
F\left(\hat{\theta}\left(x_{i}, x_{-i}\right)\right) v^{\prime}\left(x_{i}\right)-1=0 \quad \forall i=1,2, \ldots, I
$$

Given the homogeneity of land parcels and their owners, the optimum investment choices would also be identical, i.e., $\left(x_{1}^{*}, x_{2}^{*}, \ldots, x_{I}^{*}\right)=\left(x^{*}, x^{*}, \ldots, x^{*}\right)$. Let, $\left(x^{*}, x^{*}, \ldots, x^{*}\right) \equiv \mathbf{x}^{*}$. Also, from the above it follows that $x^{*}$ uniquely solves the following optimization problem: $\max _{x}\left\{F\left(\hat{\theta}\left(\mathbf{x}^{*}\right)\right) v(x)-x\right\}$. That is, $x^{*}$ uniquely solves the following first order condition:

$$
F\left(\hat{\theta}\left(\mathbf{x}^{*}\right)\right) v^{\prime}(x)-1=0
$$

To sum up, the first best is characterized by: One, choice of $x^{*}$ by each social welfare maximizing owner. Two, properties are taken if and only if $\theta \in \Theta^{*}\left(\mathbf{x}^{*}\right)$, where

$$
\Theta^{*}\left(\mathbf{x}^{*}\right)=\left\{\theta \mid \beta^{S *}(\theta)>\sum_{i=1}^{n} v\left(x^{*}\right)\right\}
$$

Three, when $\theta \in \Theta^{*}\left(\mathbf{x}^{*}\right)$, the socially best project is realized.

\footnotetext{
${ }^{26}$ It is a plausible assumption when $\theta$ stands for the growth rate. Nonetheless, we have made this assumption only for the ease of exposition. Most of our results do no depend on these assumptions.

${ }^{27}$ The existing literature has adopted similar approach towards the first best. See Giammarino and Nosal (2005), Miceli et al. (2007), Ghatak and Mookherjee (2014), Miceli (2011) and Innes (2000), among others.
} 


\section{Self-seeking Governments}

We will assume the property owners to be self-interested but will consider different types of governments. In this section, we examine the realistic case in which the government has interests of its own, which are not identical to the public interest. This view is in line with the findings of public choice theory and political economy. A government might pursue its own interests or it might cater to special interest groups. In a multi party system, it might focus on maximizing votes by catering to the interests of swing voters. In a similar vein, government administrations might be interested in 'empire building.' This changes the analysis, because under these conditions the law not only has to compensate owners and avoid inefficient levels of investment through compensation, it must also protect owners, third parties and the society at large against takings which are not in the public interest.

Contrary to some views taken in the literature on eminent domain, we hold that the level of compensation cannot be the sole driving force for the government and its branches. The state is not a profit maximizing investor. In the worst case, a liability payment for the state is a pure number without economic meaning. Therefore, it is not appropriate to apply the logic of civil liability to model decision making of a government. The analytical framework of the economic theory of civil liability holds for private persons but not for the state: politicians and bureaucrats. Therefore, we reject the view according to which the state always abstains from inefficient taking decisions, if it has to pay full damage compensation to owners. Even if the state has to fully compensate not only the owners but also all other affected parties, efficiency of taking decisions cannot be guaranteed.

We especially question the argument of 'fiscal illusion', according to which low or no compensation for taking gives the government the illusion that taking is costless thus leading to too much taking. Full compensation makes the fiscal illusion disappear. This view is prominent in the literature at least since Blume and Rubinfeld (1984). ${ }^{28}$ More recently, Epstein (2008) writes: " Just compensation ... imposes a vital price constraint on government so that unworthy social projects ... never get off the ground." Indeed, the argument of fiscal illusion is frequently used in the current literature. ${ }^{29}$

\footnotetext{
${ }^{28}$ See Blume et al. (1984), Fischel and Shapiro (1989), Fischel (2002), Dagan (2000), Dana and Merrill (2002), Merrill (2002), Serkin (2004), Niemann and Shapiro (2010), Pecorino (2011, 2013), Chang (2012), Epstein (2008), Kaplow (1986) and Göller and Hewer (2014).

${ }^{29}$ For an exhaustive account of theory see Ellickson and Been (2005). Innes (1997) argues that fiscal illusion is an unrealistic assumption. Hermalin (1995) explains why fiscal illusion does not exist.
} 
We consider the 'fiscal illusion' as an ad hoc argument. It regards the state and politicians as irrational actors who do not see things which actually exist, and disregard the information contained in an impact assessment and any other costbenefit analysis for public projects. If one assumes that the state acts in the public interest, it cannot disregard these costs irrespective of whether and how much money is transferred to the owners. Its action is then comparable to those of a caring mother, who does not disregard the costs when she takes away a toy from her child and gives it to her other child. She may make a mistake, but certainly does not suffer from a fiscal illusion. However, if we assume that the state does not act in the public interest, then votes and not dollars might be the units of measurement. To disregard compensation payments has then again nothing to do with an illusion irrespective of the damage payments.

However, we give credit to the arguments based on the budget constraint. Unlike for a private company, the parliament may limit a government's spending plans by imposing a budget constraint. In that case, neither the government nor its agencies can easily overcome this constraint. It is straightforward that with a budget constraint, an increase in the compensation amount will limit the taking activities of the state. However, we reject the argument that a tighter budget constraint must lead to better decisions from a social point of view. Below, we show that tightening the fiscal constraint can increase rather than reduce the quota of takings which are not in the public interest.

We are of the view that a government is not a perfect agent of the society. It pursues its own goals, which can be related to the societal interest but can also deviate substantially. ${ }^{30}$ This view finds ample support in the literature on public choice, political economy and the economic analysis of the public law. This body of work substantiates the view that the government's decisions are not guided solely by the consequent monetary costs. ${ }^{31}$

Literature on state liability also shows that the costs do not drive states decision making. ${ }^{32}$ For instance, Cohen (1990) argues: "We might better direct our efforts to

\footnotetext{
${ }^{30}$ This argument is consistent with the analysis presented by Fischel (1995) which shows how political motives influence government decisions to take socially undesirable behaviour and lead to excessive takings.

${ }^{31}$ See Cohen (1990), Garnett (2006), Fon and Schäfer (2007), Brennan and Boyd (2006) and Levinson (2000). Similar views were expressed by Dari-Mattiacci et al. (2010). For survey see Fischel (2015). For a discussion on political concerns among government officials see Chang (2009) and Serkin (2004).

${ }^{32}$ See Levinson (2008) for a detailed discussion.
} 
designing effective "political" markets instead of attempting to use economic signals to influence state and bureaucratic action". In similar vein, Levinson (2000) argues that "Government does not internalize costs in the same way as a private firm. Government actors respond to political incentives; not financial ones-to votes; not dollars."

\subsection{Government's Metric}

Here we formalize the idea that the government's decision making is not necessarily guided by the social interest, as discussed above. Let,

$\pi_{p}^{G}$ denote the net gains to the government from implementation of project $p$, where $p=1, \ldots, P$. The term $\pi_{p}^{G}$ depends on the direct benefit to the government from the project, which we denote by $\beta_{p}^{G}$. Plausibly $\pi_{p}^{G}$ will also depend on the net social benefits from the project, $\pi_{p}^{S}$ as defined above, to the extant the government assigns importance to the social interests. Besides, it may depend on other factors, e.g., the cost of compensation. ${ }^{33}$ Formally,

$$
\pi_{p}^{G}=\pi_{p}^{G}\left(\pi_{p}^{S}(\theta, \mathbf{x}), \beta_{p}^{G}, \vartheta_{p}\right)
$$

where $\vartheta_{p}$ denotes the other factors that might affect the government's payoff from the project; such as, the cost of compensation. In the interest of simplicity, we consider the following relationship between $\pi_{p}^{G}$ and $\pi_{p}^{S}$ :

$$
\pi_{p}^{G}(\theta, \mathbf{x})=\alpha \pi_{p}^{S}(\theta, \mathbf{x})+\epsilon_{p}
$$

where $\alpha$ and denotes the weight assigned by the government to the social interests. $^{34}$ The indexed term $\epsilon_{p}$ captures government's payoff on account of $\beta_{p}^{G}$ and also $\vartheta_{p}$, the latter stands for the other relevant factors. As a special case, $\epsilon_{p}$ can depend only on $\beta_{p}^{G}$, which in turn can be pure 'extraneous' considerations for the government.

A benevolent government would treat the compensation cost as pure transfer of money and would be guided only by the social interests. In terms of the above notations, for a benevolent government, $\alpha=1, \epsilon_{p}=0$ and therefore $\pi_{p}^{G}(\theta, \mathbf{x})=$ $\pi_{p}^{S}(\theta, \mathbf{x})$ would hold for all $p=1, \ldots, P$. However, for a self-seeking government $0 \leq \alpha \leq 1$, in general. Moreover, $\epsilon_{p}$ can be positive, zero, or negative.

The formulation as in (11) is also consistent with the agency view of the government. That is, the government as an agent of the society assigns less than full weight to the societal interests and in addition may have considerations of its own.

\footnotetext{
${ }^{33}$ In case of budget constraint, the cost of compensation imposes an opportunity cost for the government and therefore $\pi_{p}^{G}$ might depend on it.

${ }^{34}$ Our results do not depend on the assumption that $\alpha \leq 1$. Moreover, the results can easily be extended to allow $\alpha$ also to vary across projects.
} 
A situation with $\alpha \leq 1$ and $\epsilon_{p}=0$ captures the idea of project that favours all citizens alike without concentration on supporters of the ruling parties. For example, a zoo or a green belt. Similarly, $\alpha<1$ but $\epsilon_{p}$ significantly large and positive can be considered as the case in which the project concentrates on swing voters; e.g., additional slip road to the highway or a golf course for the financial supporters of the party. Note that $\pi_{p}^{S}(\theta, \mathbf{x})$ might be zero, still $\pi_{p}^{G}(\theta, \mathbf{x})$ can be positive or negative depending on the value taken by $\epsilon_{p}$. Let,

$$
\mathbb{P}^{G+}(\theta, \mathbf{x})=\left\{p^{\prime} \mid p^{\prime} \in \mathbb{P} \& \pi_{p^{\prime}}^{G}>0\right\}
$$

That is, $\mathbb{P}^{G+}$ is the set of projects for which the net gains are positive for the government. Let,

$$
\pi^{G *}(\theta)=\max \left\{\pi_{p^{\prime}}^{G}(\theta) \mid p^{\prime} \in \mathbb{P}^{G+}\right\}
$$

That is, given the state of nature $\theta, \pi^{G *}(\theta)$ denotes the maximum possible gains to the government, if it implements its pet project.

In view of the above, it is easy to see why in general we will have $\mathbb{P}^{G+}(\theta, \mathbf{x}) \neq$ $\mathbb{P}^{S+}(\theta, \mathbf{x})$, for any given $\theta$ and $\mathbf{x}$. For instance, social ranking of public-park, sliproad and Golf-course could be: public-park followed by slip-road followed by Golfcourse. In contrast, the government ranking could be: Golf-course followed by the slip-road followed by the public park.

\section{Taking in Shadow of Action for Restitution}

In this section, we will show that the liability approach towards eminent domain can guarantee none of the three properties of the first best described above. In fact, it cannot even guarantee that a taking will contribute to the social welfare at all. Next, we apply the property approach by considering the possibility of litigation for restitution of the property. The action for restitution is based on laws that regulate takings, and constitutional review of those laws in jurisdictions in which private property is not only an absolute right but also a fundamental constitutional right. For our model, we derive the propositions that these legal checks cannot guarantee that an administration realizes the best social project, but we can rule out socially undesirable projects. This relies on the assumptions that courts can restitute condemned land if the taking is not in public interest. We admit that the assumption is somewhat optimistic. However, we consider this as a reasonable assumption on the following grounds. 
First, administrative courts and constitutional courts check whether infringement of a right is 'proportional'. ${ }^{35}$ This check helps to rule out projects which do not contribute to social welfare at all (for such projects $\beta^{S}<0$ will hold). For the set of projects with positive social benefit, the proportionality check requires that the proposed condemnation of land is the mildest infringement of property for realization of the project. That is, it rules out condemnation of parcels which are not necessary for realizing the project. If the taking passes these two tests, courts still check whether the project is 'necessary' in view of the totality of social benefits as well as the costs associated with the project. ${ }^{36}$

To illustrate, consider a small town connected with an highway. If the government wants to realize another road for this town, the court might be treated it as unnecessary thus grant restitution; even though the additional road will be beneficial to some citizens and the taking happens to the mildest form of infringement for realizing the proposed project. We should add that the courts use the necessity test reluctantly. It entails weighing of costs and benefits which is generally considered to belong to the domain of legislation.

However, we would like to point out that many restitution decisions are based on rules of the administrative and constitutional law, which do not require project specific information. These rules aim at reducing the scope of wilful and politically motivated abuse of the takings power by the government, and serve as proxy for checking social desirability of a project. In several contexts, courts can meaningfully apply these to preclude socially undesirable takings without needing project specific details. Here are some examples.

The German constitutional law requires that in the context of takings, the term "common good" be clearly and specifically defined in sub-constitutional laws. Moreover, the legal authority to define the common good and the common good activities is provided only to the Federal and the State legislatures, and not the Municipalities. A rationale is that the public choice constellations related to the takings are especially important at the level of municipalities. Besides, the law defining the scope of takings must also specify the compensation. Otherwise, the taking decision

\footnotetext{
${ }^{35}$ The proportionality principle in administrative and constitutional law is used in many jurisdictions. For instance, Germany, Poland, Portugal, Spain, Israel and the European Court of Justice. This principle is not used in the US Supreme Court which however uses other comparable checks to examine whether cutting into a fundamental right can be justified on the grounds of public interest. The New eminent domain law in India, also aims to apply this principle. See Ramesh and Khan (2015).

${ }^{36}$ For a detailed discussion on the necessity doctrine in Eminent Domain, see Innes and Frisvold (2009)
} 
will be illegal.

If the rationale of taking is not precise or not in public interest per-se, it will not stand scrutiny of the constitutional court. For instance, takings for 'economic development' or for increasing the tax revenue would not pass this test. ${ }^{37}$ On the other hand, consider a class of projects for which it is difficult or impossible to provide the rationale for takings in general. If the government has a strong case for a project belonging to such a class, it can enact a specific law for a single taking for the project. An example is the taking law specifically for Airbus industries in Hamburg. For the construction of the big Airbus 380 the runway on the private airport of Airbus Industries had to be stretched. The law allowing takings for building airports for general transportation does not apply to a private airport. The parliament of the City State of Hamburg passed a specific law for the taking of land in favour of Airbus Corporation, describing in detail the social benefits of the project. In view of this so enacted law the judiciary accepted the taking decision. ${ }^{38}$

For big projects, several legal jurisdictions, including countries, require the government to undertake social impact assessment (SIA) before it can take away private properties. For instance, under the 'Land Acquisition Act 2014' of India, SIA is a pre-condition for the government to use eminent domain power. The whole point of the SIA is to assess social desirability of the project, and this information can be easily accessed by the court while adjudicating on the legality of a taking.

We conclude this discussion by arguing that there exist legal provisions enabling the courts to separate projects with negative social value from those with positive social value. For this, courts use either project specific information, e.g., SIA, or formal rules which serve as proxies. Therefore, at least in principle, the courts can use restitution to prevent socially undesirable takings.

However, we would like to emphasize that courts can restitute land only if the affected owners approach them for restitution. Moreover, a court cannot force the government to replace a project with another more desirable project. Under these assumptions a court cannot be a supervisor of the state in the sense of a benevolent social planner, who corrects the decision of a lower department. ${ }^{39}$ The law does not give such power to courts. To illustrate, assume that the socially best of three

\footnotetext{
${ }^{37}$ Leisner (2010)

${ }^{38}$ Enteignungsgesetz für die Erweiterung des Werkflugplatzes in Hamburg-Finkenwerder (Werkflugplatz-Enteignungsgesetz) Vom 18. Februar 2004

${ }^{39} \mathrm{~A}$ social planner would pick the one public project for a neighborhood with the highest social net value.
} 
alternative projects is a public park, the second best is a slip road and the third best a golf course. The first two projects have a positive and the third has a negative social value. Then if the state wants to realize the golf course we assume that the court would declare the takings as illegal if one of the affected claims restitution. But if the state wants to realize the slip road the court lacks the power to declare the slip road as illegal on the ground that there exists a socially even better project, namely the public park. The court cannot prescribe to the government, which project to choose as long as the project passes the legal test - it can only uphold or reject the proposed taking if it does not pass the required legal tests.

\subsection{The Differential Method Compensation}

Once the government has made a taking decision, an affected owner can either file for restitution or accept the compensation. A claim for restitution can be filed on the grounds that the taking decision is un-constitutional or violates rules of subconstitutional law. In this subsection, we consider the case in which compensation is fixed according to the differential method as described above. This method results in 'full' compensation for the affected owners, as under civil liability approach. This method of fixing compensation has close parallel to the economic concept of restoring a victim's utility level prior to the incident of damage. It is pertinent to mention that compensation according to differential method will be greater than the "market value', in general.

Specifically, compensation according the 'differential method' will be $c_{i}\left(x_{i}\right)=$ $v\left(x_{i}\right)$ for all $i=1, \ldots, I$. This means that an owner's ex-post payoff is $v\left(x_{i}\right)$, regardless of whether the government uses takings power or not. So, an owner $i$ will choose $x_{i}$ to maximize: $\max _{x_{i}}\left\{v\left(x_{i}\right)-x_{i}\right\}$. Privately optimum investment level is the solution to the following first order condition:

$$
v^{\prime}\left(x_{i}\right)-1=0 .
$$

Let $x_{i}^{F C}$ be the solution. Clearly, the level of investment will be the same across owners, say $x^{F C}$. Comparison of (8) with (13) in view of $\widetilde{\Theta}^{*}\left(\mathbf{x}^{*}\right) \subset[\underline{\theta}, \bar{\theta}]$ implies that:

$$
x^{F C}>x^{*}
$$

That is, chosen investment levels will be greater than the first best levels of investment. As to the taking decision, since there are no budget constraints, so the government will take away properties whenever $\mathbb{P}^{G+}\left(\theta, \mathbf{x}^{F C}\right)$ is non empty. Formally, the takings set is

$$
\Theta^{F C}\left(\mathbf{x}^{F C}\right)=\left\{\theta \mid \mathbb{P}^{G+}\left(\theta, \mathbf{x}^{F C}\right) \neq \emptyset\right\}
$$


This result does not change if the law provides an action for restitution as long as compensation is full. This is so because, under full compensation, each of the owner will invest $x^{F C}$. However, none of the affected owners has an incentive to seek restitution. ${ }^{40}$ Consequently, the takings are not subject to any meaningful scrutiny, and the government would get away with all takings in its interest, whether socially desirable or not. This situation is aptly described as 'dulde und liquidiere' (tolerate and cash in) in the German legal literature on state liability. It captures the paradox that full compensation lulls the affected citizens into inaction against a wilful state, thereby enabling the state to abuse the eminent domain power with impunity.

Proposition 1 If the owners are entitled to 'full compensation', the outcome cannot be efficient with or without an action for restitution: Owners will engage in excessive investment and the government will realize all projects in its interest.

In the following we show that restitution in combination with less than full compensation can lead to a superior outcome.

\section{$5.2 \quad$ Under-compensation}

In this section, we assume that the courts have the power to subject the taking decisions to scrutiny (action for restitution). Moreover, if there is litigation against a taking, the legal rules lead to court decisions which allow a taking if and only if it contributes to the social welfare, i.e., if and only if the social benefit from the project will be greater than the cost imposed on the property owners and the society at large. In that case, a claim to restitution ceases to exist, and the owners have claim only for compensation damages. When the social benefit is less than the opportunity costs, the court will treat a taking as unlawful leading to restitution of properties to the owners (see the discussion in the beginning of Section 5).

In Section 2 above, we described how compensation for takings differs from a civil liability claim. Compensation for taking is less well defined. Often it is described as 'fair' compensation, market value compensation, etc. In any case, the taking compensation is usually less than full compensation, in some cases significantly so. ${ }^{41}$ We formalize this idea by considering two forms of under-compensation: first, the compensation is a constant fraction of full compensation; second, the compensation is a fixed quantity. In either case, our focus will be on a situation in which the under-compensation incentivises the owners to seek restitution.

\footnotetext{
${ }^{40}$ We assume that the litigation cost is small but positive.

${ }^{41}$ Somin (2012), Singh (2012), and Munch (1976)
} 
Assume that the investment levels are positive. When compensation is less than full, a taking will leave the owners worse-off. Further, if the litigation costs are small, each owner will have an incentive to initiate an action for restitution. If there is an action for restitution, by assumption the court will compare $\beta_{p}^{S}(\theta)$ with $\sum_{i=1}^{I} v\left(x_{i}\right)$ and allow the taking iff $\beta_{p}^{S}(\theta)>\sum_{i=1}^{I} v\left(x_{i}\right)$. This means that if the government takes up any of the politically preferred but socially undesirable projects, the owners will successfully seek restitution. Since, none of these projects will pass muster of judiciary scrutiny. So, government will not initiate a taking for socially undesirable projects in the first place. Therefore, the following conclusion emerges. A project can be realized only if increases the social welfare.

In general, the project choice by government and hence the investment decisions by the owners will depend on the exact nature of relationship between the political and the social preferences. Formally put, the outcome depends on the relationship between the sets $\mathbb{P}^{S+}(\theta, \mathbf{x})$ and $\mathbb{P}^{G+}(\theta, \mathbf{x})$.

A crucial question is whether and under which conditions will socially desirable and politically preferred projects co-exist. Below we consider several leading cases on this point. The first case where the two co-exist and the second is where they don't.

\subsubsection{Socially Desirable and Politically Preferable Projects Coexist}

Next we consider the case where political preferences are allowed to be different from the societal interests. However, whenever the socially preferred projects exist, at least one of them is of interest to the government. Formally put: For any given $\mathbf{x}$

Scenario 1: $\mathbb{P}^{G+}(\theta, \mathbf{x}) \cap \mathbb{P}^{S+}(\theta, \mathbf{x}) \neq \emptyset$, whenever $\mathbb{P}^{S+}(\theta, \mathbf{x}) \neq \emptyset$.

Let us start by analyzing the project choice under Scenario 1. As argued above under less than full compensation the owners have incentive to initiate an action for restitution against inefficient takings. Therefore, a taking happens only if it contributes to the common good. Formally, given $\mathbf{x}$, at $t=2$ the taking is possible only if the realized state of nature $\theta$ is such that $\mathbb{P}^{S+}(\theta, \mathbf{x})$ is not empty - when $\mathbb{P}^{S+}(\theta, \mathbf{x})=\emptyset$ government will not succeed in taking away of the properties. For a detailed examination of the project choice by the government at $t=2$, let

$p^{S *}$ denote the socially best project;

$p^{G *}$ denote the politically most preferred project.

Clearly, both $p^{S *}$ and $p^{G *}$ depend on the state of nature at $t=2$. 
Recall, by assumption, $\mathbb{P}^{S+}(\theta, \mathbf{x}) \neq \emptyset$ implies $\mathbb{P}^{G+}(\theta, \mathbf{x}) \cap \mathbb{P}^{S+}(\theta, \mathbf{x}) \neq \emptyset$. When $\mathbb{P}^{S+}(\theta, \mathbf{x}) \neq \emptyset$ any one of the following four possible scenarios can arise.

First, $p^{S *}=p^{G *}$, i.e., the socially most desirable project also happens to be the politically most preferred project. The government can and will go for project $p^{G *}$.

Second, $p^{S *} \neq p^{G *}$ but $\left\{p^{S *}, p^{G *}\right\} \subset \mathbb{P}^{G+}(\theta, \mathbf{x}) \cap \mathbb{P}^{S+}(\theta, \mathbf{x})$. That is, the socially best project is not the pet project of the government. Even though $p^{G *}$ is not socially best, it leads to higher social welfare, and thereby will pass the legal test. Therefore, the government will choose to realize its pet project.

Third, $p^{S *} \neq p^{G *}$ only $p^{G *} \in \mathbb{P}^{G+}(\theta, \mathbf{x}) \cap \mathbb{P}^{S+}(\theta, \mathbf{x})$. In this case, the government's most favored project will be realized without any objection from the judiciary.

Fourth, $p^{S *} \neq p^{G *}$ and only $p^{S *} \in \mathbb{P}^{G+}(\theta, \mathbf{x}) \cap \mathbb{P}^{S+}(\theta, \mathbf{x})$. In this case, the government's most favored project will not be allowed by the judiciary. However, the government can successfully realize its most preferred project in the set $\mathbb{P}^{G+}(\theta, \mathbf{x}) \cap$ $\mathbb{P}^{S+}(\theta, \mathbf{x})$. Note that the realized project might or might not be the $p^{S *}$. In the other words, the chosen project doesn't have to be the socially most desirable project.

To sum up, under Scenario 1, at $t=2$ whenever a taking happens it will enhance the social welfare. That is, the claim in Proposition 2 will hold.

Proposition 2 Suppose Scenario 1 holds. Under restitution with less than full compensation, a taking happens if and only if it increases the social welfare. However, in general the project choice is not the first best.

From the above it should be noted that whenever $\mathbb{P}^{S+}(\theta, \mathbf{x}) \neq \emptyset$ some project will be taken up, thought it might not be the most efficient one. On the other hand, when $\mathbb{P}^{S+}(\theta, \mathbf{x})=\emptyset$, the government cannot succeed in taking. So, from the perspective of $t=1$, the probability of taking is the same as the probability that the set $\mathbb{P}^{S+}(\theta, \mathbf{x}) \neq \emptyset$. Using the above notation, this probability is $F(\hat{\theta}(\mathbf{x}))$. Keeping this in mind, we turn to the issue of investments. We assume that all individual optimization problems are concave with a unique interior solution.

To see why the fixed compensation does not induce efficient investment, assume that the property owners other than owner $i$ have all opted for $x^{*}$. So, the selfinterested optimization problem for owner $i$ becomes:

$$
F\left(\hat{\theta}\left(x_{i}, x_{-i}^{*}\right)\right) v\left(x_{i}\right)+\left[1-F\left(\hat{\theta}\left(x_{i}, x_{-i}^{*}\right)\right)\right] \bar{c}_{i}-x_{i},
$$

where $\bar{c}_{i}$ is the amount of compensation paid to the owner $i=1, \ldots, I$. An interior solution identified by the following first order condition:

$$
F\left(\hat{\theta}\left(x_{i}, x_{-i}^{*}\right)\right) v^{\prime}\left(x_{i}\right)+F^{\prime}\left(\hat{\theta}\left(x_{i}, x_{-i}^{*}\right)\right)\left[v\left(x_{i}\right)-\bar{c}_{i}\right]-1=0,
$$


where $F^{\prime}\left(\hat{\theta}\left(x_{i}, x_{-i}^{*}\right)\right)=\frac{\partial F\left(x_{i}, x_{-i}^{*}\right)}{\partial x_{i}}=f\left(\hat{\theta}\left(x_{i}, x_{-i}^{*}\right)\right) \frac{\partial \hat{\theta}\left(x_{i}, x_{-i}^{*}\right)}{\partial x_{i}}>0$ for all $x_{i}, i=1, \ldots, I{ }^{42}$ Rearranging, from the above we get

$$
F\left(\hat{\theta}\left(x_{i}, x_{-i}^{*}\right)\right) v^{\prime}\left(x_{i}\right)-1=-F^{\prime}\left(\hat{\theta}\left(x_{i}, x_{-i}^{*}\right)\right)\left[v\left(x_{i}\right)-\bar{c}_{i}\right] .
$$

Comparing (9) and (16), we can see that in general $x^{*}$ is not a best response by the owner $i$. Therefore, choice of efficient investment by every owner is not a Nash Equilibrium. Moreover, if $c=0$ then it can be seen that privately optimum level of investment is greater than $x^{*}$. In any case, the choice of investments is not efficient, in general.

A less than full compensation means $c_{i}\left(x_{i}\right) \leq v\left(x_{i}\right)$. Let $c_{i}\left(x_{i}\right)=\gamma v\left(x_{i}\right)$, where $\gamma \leq 1$. Now, for any given $x_{-i}$, at $t=1$ owner $i$ will decide on investment by solving:

$$
\max _{x_{i}}\left\{F\left(\hat{\theta}\left(x_{i}, x_{-i}\right)\right) v\left(x_{i}\right)+\left[1-F\left(\hat{\theta}\left(x_{i}, x_{-i}\right)\right)\right] \gamma v\left(x_{i}\right)-x_{i}\right\} .
$$

When an interior Nash equilibrium exists, it is identified by the following system of first order conditions:

$$
(1-\gamma)\left[F\left(\hat{\theta}\left(x_{i}, x_{-i}\right)\right) v^{\prime}\left(x_{i}\right)+F^{\prime}\left(\hat{\theta}\left(x_{i}, x_{-i}\right)\right) v\left(x_{i}\right)\right]+\gamma v^{\prime}\left(x_{i}\right)-1=0,
$$

where $i=1, \ldots, I$.

We can ensure existence of a Nash equilibrium by assuming $\frac{\partial^{2} F(\mathbf{x})}{\partial x_{i} \partial x_{j}} \geq 0$ for all $i, j=1, \ldots, I$. Recall, the probability of socially efficient taking decreases as individual investments go up, i.e., $\frac{\partial F(\mathbf{x})}{\partial x_{i}}>0$ for all $i=1, \ldots, I$. Assumption $\frac{\partial^{2} F(\mathbf{x})}{\partial x_{i} \partial x_{j}} \geq$ 0 means that the individual investments are either independent or complementary in terms of their effect on probability of socially efficient taking. ${ }^{43}$ The assumption is plausible. ${ }^{44}$ Under this assumption, the individual choices at $t=1$ induce a 'super-modular' game, and hence an equilibrium exists. For details see Appendix.

However, generally, in an equilibrium owners will not choose the first best level of investment. To see why, assume that $x_{-i}=x_{-i}^{*}$, i.e., owners other than $i$ have

\footnotetext{
$42 \frac{\partial \beta^{S *}(\theta)}{\partial \theta}>0$ implies $\frac{\partial \hat{\theta}(\mathbf{x})}{\partial x_{i}}>0$. Therefore, $\frac{\partial F(\mathbf{x})}{\partial x_{i}}>0$.

${ }^{43}$ Investments are (weakly) complementary if the marginal effect of investment by a property owner on the probability of no-taking increases (weakly) with the investments by the other owners.

${ }^{44}$ In general, investment in a land parcel creates positive spillover effects for the neighbouring properties. At the same time, the value of a parcel increases as investments in the nearby plots go up. Therefore, the investment levels are complementary in terms of their effect on the value and therefore opportunity cost of taking of a neighborhood. Increase in the value makes the investments complementary in terms of their effect on the probability of socially efficient taking.
} 
opted for $x^{*}$ each. Now, upon rearranging (18), the first order condition for owner $i$ can be expressed as:

$$
\begin{aligned}
F\left(\hat{\theta}\left(x_{i}, x_{-i}^{*}\right)\right) v^{\prime}\left(x_{i}\right)-1= & -(1-\gamma) F^{\prime}\left(\hat{\theta}\left(x_{i}, x_{-i}^{*}\right)\right) v\left(x_{i}\right) \\
& -\gamma\left[1-F\left(\hat{\theta}\left(x_{i}, x_{-i}^{*}\right)\right)\right] v^{\prime}\left(x_{i}\right) .
\end{aligned}
$$

Comparing (9) and (19), we can see that $x^{*}$ is not a best response by the owner $i$, except by chance. The privately optimal investment level is greater than $x^{*}$. Therefore, choice of efficient investment by every owner is not a Nash Equilibrium.

In general, under-compensation unleashes conflicting effects on individual investment decisions. On one hand, it induces owners to invest more than $x^{*}$. Since a taking leaves them worse off, the owners want to over-invest to reduce the likelihood of a taking. At the same time, the owners know that if a taking actually happens, they will loose out on at least a part of the benefit from (excessive) investment. This countervailing force can work to mitigate the problem of excessive investment. Under plausible conditions the restitution with under-compensation induces investment choices that are more efficient than is the case with full compensation.

Specifically, Proposition 3 below shows that individual investment choices will be between $x^{*}$ and $x^{F C}$ when $\frac{\partial F(\mathbf{x})}{\partial x_{i}}$ is 'small', i.e., when the marginal effect of individual investment decisions on the probability of taking is small. ${ }^{45}$ Note that this assumption is about the marginal effect of investment choice by an individual owner - the combined effect can be significant. The assumption is plausible when the taking affects a large number of property owners. In that case, investment by any one individual will not have significant bearing on the opportunity cost and therefore the taking decision. The assumption is also plausible when most of the individual valuations are on account of the land itself, rather than the superstructures and other fixed investments. For instance, when taking involves non-residential and non-commercial properties, e.g., agricultural land.

For Scenario 1, we have the following result. A formal and complete proof is provided in the Appendix.

Proposition 3 When Scenario 1 holds, under restitution with less than full compensation, individual investments will be greater than $x^{*}$ but less than $x^{F C}$.

Next, we make room for the possibility for states of nature in which no project is of political interest, even though there are socially desirable projects. Formally,

\footnotetext{
${ }^{45}$ This assumption is not a necessary conditions for our results to hold.
} 
suppose there is at least one state of nature, say $\theta^{\prime}$, such that the set $\mathbb{P}^{G+}\left(\theta^{\prime}, \mathbf{x}\right) \cap$ $\mathbb{P}^{S+}\left(\theta^{\prime}, \mathbf{x}\right)$ is empty even when $\mathbb{P}^{S+}\left(\theta^{\prime}, \mathbf{x}\right)$ is non-empty. However, we require that there are possible states of nature in which the political and the social preferences can find a middle ground. In other words, there exists at least one state of nature, say $\theta^{\prime \prime}$, in which the sets $\mathbb{P}^{G+}\left(\theta^{\prime \prime}, \mathbf{x}\right) \cap \mathbb{P}^{S+}\left(\theta^{\prime \prime}, \mathbf{x}\right)$ and $\mathbb{P}^{S+}\left(\theta^{\prime \prime}, \mathbf{x}\right)$ are both non-empty. That is:

Scenario 2: For any given $\mathbf{x}$,

$\exists \theta^{\prime} \in \Theta$ such that $\mathbb{P}^{S+}\left(\theta^{\prime}, \mathbf{x}\right) \neq \emptyset$ but $\mathbb{P}^{G+}\left(\theta^{\prime}, \mathbf{x}\right) \cap \mathbb{P}^{S+}\left(\theta^{\prime}, \mathbf{x}\right)=\emptyset$, and $\exists \theta^{\prime \prime} \in \Theta$ such that $\mathbb{P}^{G+}\left(\theta^{\prime \prime}, \mathbf{x}\right) \cap \mathbb{P}^{S+}\left(\theta^{\prime \prime}, \mathbf{x}\right) \neq \emptyset .46$

It is easy to see that under Scenario 2 also, at $t=2$ a taking can happen only if it will enhance the social welfare. Moreover, if a taking happens the project choice will be as under Scenario 1, for any given profile of individual investments. That is, conditional on taking, as far as the government's decision at date $t=2$ concerned, the claim in Proposition 2 will hold. In fact, as the following proposition shows, the investment choices will also be between $x^{*}$ and $x^{F C}$. For proof see the Appendix.

Proposition 4 For Scenario 2, under restitution with less than full compensation the individual investments will be greater than $x^{*}$ but less than $x^{F C}$. A taking happens only if it contributes to the social welfare.

Therefore, in Scenarios 1 and 2, the less-than-full compensation results in investment levels closer to the first levels, compared to the case of full compensation. Moreover, every taking contributes to the social welfare. In fact, using a technical assumption we prove the following claim.

Proposition 5 Under Scenarios 1 and 2, the social welfare (common good) under restitution with under-compensation is higher than the outcome under full compensation (with or without the availability of restitution).

Under Scenario 1, the outcome can be further improved if the constitutional or sub-constitutional law mandates that the opportunity cost of taking be calculated based on efficient levels of investment. ${ }^{47}$ Specifically, suppose while assessing the opportunity cost of a taking, if the judiciary and the government are required by the law to ignore the excessive investment by property owners. In that case, restitution with under-compensation can induce an outcome in which the investments are first best efficient, and a taking happens if and only if it improves social welfare. Moreover, there is no litigation. Formally, we have the following result.

${ }^{46} \mathbb{P}^{G+}(\theta, \mathbf{x}) \cap \mathbb{P}^{S+}(\theta, \mathbf{x}) \neq \emptyset$ can hold only if $\mathbb{P}^{S+}(\theta, \mathbf{x}) \neq \emptyset$ holds.

${ }^{47}$ That it, the law adopts an approach similar to 'reasonable-man' standard under the tort law. 
Proposition 6 Suppose Scenario 1 holds and the judiciary allows takings iff $\beta^{S *}(\theta)>$ $\sum_{i=1}^{I} v\left(x_{i}^{*}\right)$. There is an equilibrium such that the investments are efficient, and the takings happens only if it improves the social welfare. There is no litigation.

Formally we show that under the conditions of the proposition, there exists a Nash equilibrium in which each owner chooses efficient investment, i.e., $x^{*}$ and takings by the government happens if and only when it is socially beneficial i.e. $\theta \in \Theta^{*}\left(x^{*}\right)$. Moreover, the equilibrium is sub-game perfect.

To sum up, analysis in this subsection shows that the outcome under less than full compensation with the action of restitution departs from the first best. There is excessive investment by the owners. Consequently, the number of takings is less than the first best. In general, the project choice is also not the first best.

However, on two counts the equilibrium outcome under less than full compensation with the action of restitution is better than the outcome under the full compensation case: One, investment levels are relatively efficient than under full compensation; two, the taking happens if and only if it contributes to the social welfare. These claims hold vis-a-vis the full compensation liability regime without provision of injunctive relief. Outcome could be further improved under Scenario 1 if rules of administrative law enjoins the government not to take excessive into account when assessing the net social gains from a project.

\subsubsection{Socially Desirable and Politically Preferable Projects Do not Co- exist}

Here, we consider the remaining situations. The first case when the political preferences are rather different from the social interest. In extreme, no socially desirable project is politically interesting, independent of the circumstances and investment levels. That is, the following scenario holds:

Scenario 3: $\mathbb{P}^{G+}(\theta, \mathbf{x}) \cap \mathbb{P}^{S+}(\theta, \mathbf{x})=\emptyset$, for all $\mathbf{x}$ and all $\theta \in \Theta$.

Under such unusual conditions, no project will be realized, and the uniquely best investment choice for each owner will be to choose $x$ to maximize $\{v(x)-x\}$, i.e., to choose $x^{F C}$, as defined above.

Scenario 4: There exists $\mathbf{x}$, such that: $\mathbb{P}^{G+}(\theta, \mathbf{x}) \cap \mathbb{P}^{S+}(\theta, \mathbf{x})=\emptyset$, for all $\theta \in \Theta$.

For illustration, suppose the above holds for $\mathbf{x}=\mathbf{x}^{F C}$, i.e., $\mathbb{P}^{G+}\left(\theta, \mathbf{x}^{F C}\right) \cap$ $\mathbb{P}^{S+}\left(\theta, \mathbf{x}^{F C}\right)=\emptyset$, for all $\theta \in \Theta$. This would mean that if each owner invests $x^{F C}$ 
then there is no project that contributes to social welfare and also interests the government. However, the intersection $\mathbb{P}^{G+}(\theta, \mathbf{x}) \cap \mathbb{P}^{S+}(\theta, \mathbf{x})$ might be non-empty for some other $\mathbf{x}$.

In principle, such a situation might arise if due to the high investments (recall, $\left.x^{F C}>x^{*}\right)$ the opportunity cost of a taking is always greater than the social benefit, i.e., $\mathbb{P}^{S+}\left(\theta, \mathbf{x}^{F C}\right)=\emptyset$ for all $\theta \in \Theta$, or $\mathbb{P}^{G+}\left(\theta, \mathbf{x}^{F C}\right)=\emptyset$ for all $\theta \in \Theta$. Therefore $\mathbb{P}^{G+}\left(\theta, \mathbf{x}^{F C}\right) \cap \mathbb{P}^{S+}\left(\theta, \mathbf{x}^{F C}\right)=\emptyset$ will hold for all $\theta \in \Theta$.

Under such a situation, each owner indeed would want to invest $x^{F C}$. Since due to less than full compensation, owners want to reduce the probability of takings. They can reduce the probability to zero simply by choosing $x^{F C}$ each. When the probability of taking is zero, the privately optimum level of investment is nothing but $x^{F C}$. Formally, as Proposition 7 shows there is a sub-game perfect Nash equilibrium in which each owner will invest $x^{F C}$ and government will abstain from taking altogether. The proof is in the Appendix.

Proposition 7 Suppose $\mathbb{P}^{G+}\left(\theta, \mathbf{x}^{F C}\right) \cap \mathbb{P}^{S+}\left(\theta, \mathbf{x}^{F C}\right)=\emptyset$, for all $\theta \in \Theta$ holds. Under the restitution with less than full compensation, each owner will invest $x^{F C}$ and there will be no takings.

Under the conditions of Proposition 7, the result is public under-investment but also the avoidance of public projects which are detrimental to society. Given this departure from the first best level of private investment of landowner is, however, socially optimal.

We conclude the analysis by noting that in principle Scenario 4 might hold for some other levels of investment. Moreover, under Scenario 4 and its variants, there might exists several equilibria, depending on the context. However, we consider such situations to be rare because they imply that the government's preference is so far removed from the social interest that the government is never interested in a socially beneficial project, in any state of the world. Therefore, we do not investigate such situations in greater detail as we do not regard them of high policy interest.

\section{Benevolent Governments}

In this section, we consider public use takings by a benevolent government. We analyze the effect of compensation rules on behaviour of the government and the property owners. ${ }^{48}$

\footnotetext{
${ }^{48}$ For further discussion on Benevolent government ,See Fischel and Shapiro (1989) and Hermalin (1995). However, as argued earlier, modern public choice theory suggests that this benevolent view of the government is an unrealistic case (See Mueller (1989) and Innes (1997)).
} 
A benevolent government will go for takings iff the state of the nature $\theta$ is such that the net social benefit from the best possible project is positive i.e., iff $\beta^{S *}(\theta)>\sum_{i=1}^{I} v\left(x_{i}\right)$. Formally, for any given $\mathbf{x}=\left(x_{i}, x_{-i}\right)$, the the government will go for the taking iff:

$$
\theta \in \Theta^{*}(\mathbf{x})=\left\{\theta \mid \beta^{S *}(\theta)>\sum_{i=1}^{I} v\left(x_{i}\right)\right\}
$$

This means that at $t=1$, the probability that taking will not happen is equal to $F\left(\hat{\theta}\left(x_{i}, x_{-i}\right)\right)$, regardless of the compensation amount paid to owners, since a benevolent government will regard compensation as pure transfer.

Now, consider the case of fixed compensation and no-compensation at all. The existing literature has argued that property owners can be incentivised to choose socially optimum investment levels under these compensation schemes. In contrast, we show that normally this result does not hold. Indeed, fixed-compensation schemes including zero-compensation cannot induce efficient investment by the owners. To see why, assume that all owners except $i$ have chosen the socially optimal investment. So, owner $i$ 's investment choice will solve the following:

$$
\max _{x_{i}}\left\{F\left(\hat{\theta}\left(x_{i}, x_{-i}^{*}\right)\right) v\left(x_{i}\right)+\left[1-F\left(\hat{\theta}\left(x_{i}, x_{-i}^{*}\right)\right)\right] \bar{c}_{i}-x_{i}\right\},
$$

where $\bar{c}_{i}$ is the compensation paid to owner $i$. This is nothing but the optimization problem (14) with corresponding first order condition as in (16). We have already seen that when $\bar{c}_{i}=0$, choice of $x^{*}$ is not individually optimal for owner $i$. Indeed, the privately optimum level of investment is greater than $x^{*}$. This happens because more investment increases the opportunity costs of taking and therefore reduces the probability that a benevolent government, which weighs all costs and benefits will take the land. ${ }^{49}$

In general, the level of privately optimum investments can be greater or less than $x^{*}$, depending on the quantum of the fixed-compensation. The only exception is the case when $\bar{c}_{i}$ is fixed exactly at $v\left(x^{*}\right)$. Therefore, choice of efficient investment by every owner is not a Nash Equilibrium (unless $\bar{c}=v\left(x^{*}\right)$ ).

Proposition 8 When government is benevolent, generally a fixed compensation scheme, including zero-compensation, cannot guarantee the first best outcome.

\footnotetext{
${ }^{49}$ This result parallels the claims in Riddiough (1997), Innes (1997, 2000), Polasky and Doremus (1998), Bohn and Deacon (2000), Serkin (2004), Schieffer (2007), and Innes and Frisvold (2009). These works have argued that no compensation can cause undesirable consequences such as excessive investment. Nosal (2001) although focusing on physical takings, argues that no-compensation results in a non-optimal outcome. Pecorino (2011) makes a similar claim.
} 
It is pertinent to point out that this result differs from the claims in several papers that the fixed compensation schemes can induce efficient investments. This strand of the literature assumes that the probability of taking is independent of the investment choices. ${ }^{50}$ In contrast, in our model this probability depends on the investment levels.In our view this is a necessary consequence if the government is benevolent.

However, under compensation combined with an action for restitution still delivers an outcome better than the civil liability (full compensation). Here is the basic idea. When the government is benevolent, the probability of no-taking is given by $F\left(\hat{\theta}\left(x_{i}, x_{-i}\right)\right)$, for any given profile of investments, $\left(x_{i}, x_{-i}\right)$. So, for owner $i$, the optimization problem is as in (17). Therefore, it is straightforward to see that a claim similar to Proposition 5 holds. That is, individual investments are greater than $x^{*}$ but less than $x^{F C}$.

Moreover, at $t=2$ the benevolent government will go for takings if and only if it contributes to the social welfare. Moreover, the socially best project is realized. Consequently, the equilibrium outcome under less than full compensation with restitution is better than the outcome under the full compensation. Formally, we have the following proposition. Proof is in the Appendix.

Proposition 9 When the government is benevolent, the social welfare (common good) under restitution with under-compensation is higher than the outcome under full compensation (with or without the availability of restitution).

It is should be noted that here the first best is not achieved, even with the benevolent government. Under-compensated investors over-invest and the benevolent state takes the entire opportunity cost of these investments into account when making the taking decision. Therefore, the expected number of realized projects is less than in the case of the first best.

Miceli et al. (2007), Göller and Hewer (2014), Schweizer (2017) and Blume et al. (1984) also provide similar mechanisms to achieve the first best. However, these works assume that there is only property owner and/ or do not model the issue of project choice.

However, it is easy to design schemes to achieve the first best outcome for our setting. For example, if the government could credibly commit to pay a fixed compensation equal to $v\left(x^{*}\right)$ and go for taking whenever $\beta^{S *}(\theta)>\sum_{i=1}^{I} v\left(x_{i}^{*}\right)$, regardless

\footnotetext{
${ }^{50}$ See Blume and Rubinfeld (1984), Paul (1987), Epstein (1985, 1995, 2008), Burrows (1991), Miceli (1991), Farber (1992), Fischel (1995), Yandle (1995), Fischel and Shapiro (2011), Hermalin (1995), Miceli et al. (2007), Miceli (2011) and others. Also, See Munch (1976), Brennan and Boyd (2006), Pecorino (2011, 2013), Miceli and Segerson (1994)
} 
of the actual choice of the investments, equilibrium outcome will be the first best. Another mechanism will require zero-compensation and a credible commitment from the government to ignore the opportunity cost of excessive investment. Strictly speaking such schemes are not consistent with the assumption of a benevolent government - for these mechanism to work the government needs to be non-benevolent at least off the equilibrium path. In any case, such mechanisms are not a focus area of this paper.

\section{Budget Constraints and Takings}

So far we had focused only on one instance of takings, involving $I$ contiguous properties. Further, we had assumed that the government has enough funds in its budget to finance the project of interest. In the real world, governments use eminent domain power in different areas/neighborhoods to realize different projects in any given period of time, and the governments face budget constraints. Therefore, a government may not be able to fund all the projects.

Contrary to some of the views in the literature the proportion of inefficient takings can increase as the budgetary constraint becomes binding and tighter. Tightening the budget constraint cannot guarantee that fewer socially undesirable projects will be realized. ${ }^{51}$

For the ease of illustration, consider a city with three neighborhoods. Let neighborhoods be denoted by $N ; N=1, \ldots, 3$. Suppose, the following three projects are under consideration by the government: public-park, slip-road and Golf-course. In principle, the government can take up any of the three projects at any one of the three locations available. However, as explained in the model, at one neighborhood only one project can be realized. Therefore, if the government wants to realize all three projects, it will end up using eminent domain power in all three neighborhoods.

Assume that for each neighborhood, the social ranking of projects is publicpark followed by slip-road followed by Golf-course. In contrast, the government ranking is: Golf-course followed by the slip-road followed by the public park, in each neighborhood. Moreover, $\mathbb{P}^{G+}=\{$ Golf-course, slip-road and public-park $\}$ but $\mathbb{P}^{S+}=\{$ public-park, slip-road $\}$.

That is, Golf-course project is not in the social interest, though it is high on the

\footnotetext{
${ }^{51}$ On the contrary, Schieffer (2007) models governments facing budget constraints with limited powers of taxation. He concludes that a full compensation rule leads to inefficiency in the form of under regulation. The model further shows that the project which contributes most to aggregate welfare will be chosen.
} 
government's agenda. For simplicity assume that the total costs for the government are roughly comparable across projects, including the cost of compensation.

Now, consider a the regime of full compensation. If the government faces no budget constraints, it can implement all three projects as the owners will not seek restitution. In such a scenario, the proportion of inefficient takings will be $1 / 3$. However, if the government can fund only two projects, it will choose to implement Golf-course and the slip-road projects. That is, the number of socially undesirable projects remains unchanged. However, the proportion of inefficient takings will increase to $1 / 2$.

Next, consider the regime of restitution with under compensation as described in Section 6. Under this regime, if the government faces no budget constraint, it will realize only two projects; namely the slip-road and public-park. Now, suppose due to tightening of budget constraint, the government can realize only two projects, there will be no change in the outcome. Moreover, if the budget constraint becomes even tighter so that the government can fund only one project, it will go for slip-road, which is not socially best but still leads to increased social welfare. In contrast, under full compensation if the government can realize only one project, it will go for golfcourse, which is socially inefficient. Therefore, even when the government is faced with a budget constraint, the outcome under restitution with under-compensation is better than the outcome under full compensation.

This is a somewhat simplistic account, but the main argument is expected to prevail more generally, including when taking can be done in a larger number of neighborhoods.

\section{Private Purpose Takings}

Finally, we consider a situation where it might be reasonable to use full compensation. The situation we have in mind is when the state does not use the acquired land but transfers it to a profit maximizing company, for instance agricultural land might be taken for an industrial plant. The key distinction assumed here is that the cost of compensation is directly or indirectly borne by a private and profit maximizing entity. ${ }^{52}$ In this case a full damage award according to the differential method can lead to efficient takings and the efficiency of the outcome does not dependent on the owners filing for restitution. Full compensation guarantees that the property is

\footnotetext{
${ }^{52}$ We rule out the cases in which the private entity benefiting from the taking does not bear the full burden of compensation. For details See Singh (2012) and Somin (2015).
} 
transferred to a higher valued user according to the well-known Calabresi-Melamed proposition, since full compensation guarantees that properties are transferred to a more efficient use. However, this requires that compensation to the owners covers all damages including third party effects, if any.

Given that the compensation is full, each owner will choose investment level $x^{F C}$, as defined above. That is, the owners will choose excessive investment due to full compensation. Since the cost of land is borne by the private entity, the takings will used only if the resultant benefit is greater than the cost of compensation. Therefore, a private project will be realized only if:

$$
\beta_{p}^{C}(\theta)>\sum_{i=1}^{I} v\left(x^{F C}\right),
$$

where $\beta_{p}^{C}(\theta)$ is the benefit from the project to the developer for the realized state of nature $\theta$.

To sum up, if taking is for the benefit of a private business and full compensation is paid, the taking decisions increase efficiency without an action for restitution, conditional on the given investment decisions. However, in general, the outcome will be inefficient on two counts. One, the owners will invest too much; two, not every efficient project will be realized because every efficient project might not be of political interest.

\section{Conclusions}

In this paper, we have modeled and examined effects of two salient features of the eminent domain law and its use. First, in most legal orders the compensation for taking of land property is less than full compensation according to the 'differential method' used under civil liability. Second, the government is not a perfect agent of the society. While making the taking decisions it has interests of its own which are not always the same as the social interests. Once these two features are factored in, several of the claims in the existing literature on eminent domain do not hold.

Our findings question the 'fiscal illusion' based theory of the government's behavior. We have shown that when the government is self-seeking, full compensation ensures neither that the takings will be efficient nor that the project choice will be in the social interest. On top of that there will be excessive investments by property owners. This outcome cannot be improved even if the full compensation is supplemented with a legal provision of an action for restitution.

However, the outcome is better if under-compensation is combined with the provision of restitution against unlawful takings. This combination delivers an outcome which is better than the outcome under full compensation on the following three 
counts: One, investment levels are more efficient; two, a taking happens only if it contributes to the social welfare; three, the project choice by the government is also better.

Further, we have shown that fixed-compensation schemes including no-compensation, do not ensure efficient outcome even if the government is assumed to be benevolent. However, under-compensation can still deliver outcome more efficient than the full compensation.

Finally, we have shown that if the taking is for a private investor, the full compensation to the affected parties can be a reasonable approach for efficient use of eminent domain. Similarly, full compensation might be better option if the action for restitution against unlawful takings is unavailable or ineffective.

\section{Appendix}

Proof of Proposition 3: As argued above, under less-than-full compensation, the probability of no-taking is $F\left(\hat{\theta}\left(x_{i}, x_{-i}\right)\right)$, where $\left(x_{i}, x_{-i}\right)$ is the profile of individual investments. First consider the case when $x_{i} \leq x^{F C}$ holds for all $i$. Let the compensation to owner $i$ be given by $c_{i}\left(x_{i}\right)=\gamma v\left(x_{i}\right)$. So, for any given $x_{-i}$, the optimization problem of the $i$ th owner is given by:

$$
\max _{x_{i}}\left\{\pi^{i} \equiv F\left(\hat{\theta}\left(x_{i}, x_{-i}\right)\right) v\left(x_{i}\right)+\left[1-F\left(\hat{\theta}\left(x_{i}, x_{-i}\right)\right)\right] \gamma v(\cdot)-x_{i}\right\}
$$

When $\frac{\partial^{2} F\left(\hat{\theta}\left(x_{i}, x_{-i}\right)\right)}{\partial x_{i} \partial x_{j}} \geq 0$, from $(22)$ it can be seen that $\frac{\partial^{2} \pi^{i}}{\partial x_{i} \partial x_{j}} \geq 0$ for all $i, j=1, \ldots, I$. That is, the game induced by individual optimization problems at $t=1$, becomes 'super-modular', and therefore has a Nash equilibrium. An interior equilibrium is identified by the set of first order conditions given by (18). Upon rearranging (18), we get:

$$
v^{\prime}\left(x_{i}\right)-1=(1-\gamma)\left[\left(1-F\left(\hat{\theta}\left(x_{i}, x_{-i}\right)\right)\right) v^{\prime}\left(x_{i}\right)-F^{\prime}\left(\hat{\theta}\left(x_{i}, x_{-i}\right)\right) v\left(x_{i}\right)\right],
$$

$i=1, \ldots, I$. From (23) it is obvious that that equilibrium investments depend on the $\gamma$. Also, the payoff functions are continuous in $\gamma$. Furthermore, $\frac{\partial^{2} \pi^{i}}{\partial \gamma \partial x_{i}}=$ $\left(1-F\left(\hat{\theta}\left(x_{i}, x_{-i}\right)\right)\right) v^{\prime}\left(x_{i}\right)-F^{\prime}\left(\hat{\theta}\left(x_{i}, x_{-i}\right)\right) v\left(x_{i}\right)$. Recall $\lim _{x \rightarrow 0} v^{\prime}(x)=\infty$. Therefore, for any given $x_{-i}$, for small value $x_{i},\left(1-F\left(\hat{\theta}\left(x_{i}, x_{-i}\right)\right)\right) v^{\prime}\left(x_{i}\right)$ takes very large positive value. So, $\frac{\partial^{2} \pi^{i}}{\partial \gamma \partial x_{i}}>0$ holds over a range of $x_{i}$. Also, when $F^{\prime}\left(\hat{\theta}\left(x_{i}, x_{-i}\right)\right)$ is sufficiently small, $\frac{\partial^{2} \pi^{i}}{\partial \gamma \partial x_{i}}>0$ holds. Specifically, a sufficient condition is: $F^{\prime}\left(\hat{\theta}\left(x_{i}, x_{-i}\right)\right)$ is such that at $\left(x^{F C}, x_{-i}^{F C}\right),\left(1-F\left(\hat{\theta}\left(x_{i}, x_{-i}\right)\right)\right) v^{\prime}\left(x_{i}\right)-F^{\prime}\left(\hat{\theta}\left(x_{i}, x_{-i}\right)\right) v\left(x_{i}\right)>0$ holds. In that case, $\frac{\partial^{2} F\left(\hat{\theta}\left(x_{i}, x_{-i}\right)\right)}{\partial x_{i} \partial x_{j}} \geq 0$ implies that $\frac{\partial^{2} \pi^{i}}{\partial \gamma \partial x_{i}}>0$ will hold for all $x_{i} \leq x^{F C}$ and 
$x_{-i} \leq x_{-i}^{F C}$. That is, the marginal benefit from individual investment increase with $\gamma$ for all $i=1, \ldots, I$.

Formally put, the game is super-modular and the 'single crossing property' is satisfied with respect to $\gamma$ for all $x_{i} \leq x^{F C}$ and $x_{-i} \leq x_{-i}^{F C}$. Therefore, for a Nash equilibrium, the investment levels are increasing function of $\gamma^{53}$ When $\gamma=1$, the Nash equilibrium has $x_{i}=x^{F C}$ for all $i$. For a suitable choice of $\gamma<1$, the equilibrium investments are less than $x^{F C}$ but greater than $x^{*}$. It can easily be seen that an equilibrium of the game with restriction $x_{i} \leq x^{F C}, i=1, \ldots, I$, is also an equilibrium of the game without these restrictions. A qualitatively similar argument holds for fixed (less than full) compensation.

Proof of Proposition 4 Clearly for any given $\mathbf{x}, \mathbb{P}^{G+}(\theta, \mathbf{x}) \cap \mathbb{P}^{S+}(\theta, \mathbf{x}) \neq \emptyset$ only if $\mathbb{P}^{S+}(\theta, \mathbf{x}) \neq \emptyset$. Further, $\mathbb{P}^{S+}(\theta, \mathbf{x}) \neq \emptyset$ iff $\Theta^{*}(\mathbf{x}) \neq \emptyset$. So, $\mathbb{P}^{G+}(\theta, \mathbf{x}) \cap \mathbb{P}^{S+}(\theta, \mathbf{x}) \neq \emptyset$ only if $\Theta^{*}(\mathbf{x}) \neq \emptyset$. Consequently, under Scenario 2 also, a taking will happen only if the net social gains are positive. Let, $\bar{F}\left(x_{i}, x_{-i}\right)$ denote the probability of a taking under Scenario 2. By assumption, $\exists \theta^{\prime \prime} \in \Theta$ such that $\mathbb{P}^{G+}\left(\theta^{\prime \prime}, \mathbf{x}\right) \cap \mathbb{P}^{S+}\left(\theta^{\prime \prime}, \mathbf{x}\right) \neq \emptyset$. Therefore, for any given $\mathbf{x}$, the probability of taking under Scenario 2 less than the first best case, i.e, $\bar{F}\left(x_{i}, x_{-i}\right)>F\left(x_{i}, x_{-i}\right)$, where $F\left(x_{i}, x_{-i}\right)=F\left(\hat{\theta}\left(x_{i}, x_{-i}\right)\right.$. Recall, for any given $\mathbf{x}$ the probability of taking under Scenario 1 is the same as under the first best. Clearly, $\bar{F}\left(x_{i}, x_{-i}\right)$ is a non-increasing function of $x_{i}$. For simplicity assume $\bar{F}\left(x_{i}, x_{-i}\right)$ to be a continuous and decreasing function of $x_{i}$ for all $i=1, \ldots, I$. So, for any given $x_{-i}$, under Scenario 2 when compensation is less than full, the optimization problem of the $i$ th owner is:

$$
\max _{x_{i}}\left\{\bar{F}\left(x_{i}, x_{-i}\right) v\left(x_{i}\right)+\left[1-\bar{F}\left(x_{i}, x_{-i}\right)\right] \gamma v(\cdot)-x_{i}\right\} .
$$

The corresponding set of first order conditions is:

$$
v^{\prime}\left(x_{i}\right)-1=(1-\gamma)\left[\left(1-\bar{F}\left(\hat{\theta}\left(x_{i}, x_{-i}\right)\right) v^{\prime}\left(x_{i}\right)-\bar{F}^{\prime}\left(x_{i}, x_{-i}\right) v\left(x_{i}\right)\right],\right.
$$

$i=1, \ldots, I$. Clearly, when $\frac{\partial^{2} \bar{F}\left(x_{i}, x_{-i}\right)}{\partial x_{i} \partial x_{j}} \geq 0$ the game is super-modular. Further, as $\bar{F}^{\prime}\left(x_{i}, x_{-i}\right)$ approaches zero, the right hand sides become positive. Arguing as in the case of Proposition 3, it can be seen that for a range of $\gamma<1$, there is an equilibrium in which the individually optimum investment will be between $x^{*}$ and $x^{F C}$.

Proof of Proposition 5: First consider Scenario 1. Define

$$
\Theta^{S}(\mathbf{x})=\left\{\theta \in \Theta \mid \mathbb{P}^{S+}(\theta, \mathbf{x}) \neq \emptyset\right\} \text { and } \Theta^{G}(\mathbf{x})=\left\{\theta \in \Theta \mid \mathbb{P}^{G+}(\theta, \mathbf{x}) \neq \emptyset\right\} .
$$

\footnotetext{
${ }^{53}$ See Milgrom and Roberts (1990). For a survey of the literature on this issue, see Amir (2005).
} 
Let, $\tilde{\Theta}^{G}(\mathbf{x}) \equiv \Theta \backslash \Theta^{G}(\mathbf{x})$ and $\tilde{\Theta}^{S}(\mathbf{x}) \equiv \Theta \backslash \Theta^{S}(\mathbf{x})$. From above, we know that for Scenario 1, under-compensation with restitution, implies that $\Theta^{S}(\mathbf{x}) \subseteq \Theta^{G}(\mathbf{x})$, and for given $\mathbf{x}$ taking happens iff $\theta \in \Theta^{S}(\mathbf{x})$. Moreover, when taking happens, the government realizes it most preferred project from the set $\mathbb{P}^{G+}(\theta, \mathbf{x}) \cap \mathbb{P}^{S+}(\theta, \mathbf{x}){ }^{54}$ Consider the case when $\Theta^{S}(\mathbf{x})$ is non-empty. Let $\beta_{S \cap G}^{S}(\theta)$ denote the social benefit from the government's most preferred project from the set $\mathbb{P}^{G+}(\theta, \mathbf{x}) \cap \mathbb{P}^{S+}(\theta, \mathbf{x})$.

$\beta_{G^{*}}^{S}(\theta)$ denote the social benefit from the government's pet project from the set $\mathbb{P}^{G+}(\theta, \mathbf{x})$.

The discussion preceding Proposition 2 shows that $\beta^{*}(\theta) \geq \beta_{S \cap G}^{S}(\theta) \geq \beta_{G^{*}}^{S}(\theta)$. Also, under less-than-full compensation with restitution, at $t=2$, a taking happens iff the social benefits from the project is greater than the opportunity cost of investments. Therefore, for any given profile of investments $\mathbf{x}$, the expected social benefit is given by:

$$
\int_{\tilde{\Theta}^{S}(\mathbf{x})} \sum_{i=1}^{I} v\left(x_{i}\right) f(\theta) d \theta+\int_{\Theta^{S}(\mathbf{x})} \beta_{S \cap G}^{S}(\theta) f(\theta) d \theta-\sum_{i=1}^{I} x_{i} .
$$

Assume that (26) is concave and takes maximum value at an interior point say $\mathrm{x}^{* *}{ }^{55}$ Again, at the maximum individual investments will be the same across owners. Moreover, by assumption probability of taking is less than one, so any $\mathbf{x} \geq \mathbf{x}^{F C}$ cannot be a solution. Therefore, $\mathbf{x}^{* *}<\mathbf{x}^{F C}$.

Next, suppose $\mathbf{x}^{\prime}$ denotes the vector of equilibrium investments levels under lessthan-full compensation with restitution. From Proposition 3, we know that $\mathbf{x}^{\prime}$ is a function of $\gamma$, and $\mathbf{x}^{*}<\mathbf{x}^{\prime}(\gamma)<\mathbf{x}^{F C}$. Further, from the proof of Proposition 3, we know that $\mathbf{x}^{\prime}$ can be made arbitrarily close to $\mathbf{x}^{F C}$ for $\gamma$ less than but very close to 1 . So, for a suitable choice of $\gamma<1$, we get $\mathbf{x}^{* *}<\mathbf{x}^{\prime}<\mathbf{x}^{F C}$. In view of the concavity of $(26)$, we get

$$
\begin{aligned}
\int_{\tilde{\Theta}^{S}\left(\mathbf{x}^{\prime}\right)} I v\left(x^{\prime}\right) f(\theta) d \theta+ & \int_{\Theta^{S}\left(\mathbf{x}^{\prime}\right)} \beta_{S \cap G}^{S}(\theta) f(\theta) d \theta-I x^{\prime}> \\
& \int_{\tilde{\Theta}^{S}\left(\mathbf{x}^{F C}\right)} I v\left(x^{F C}\right) f(\theta) d \theta+\int_{\Theta^{S}\left(\mathbf{x}^{F C}\right)} \beta_{S \cap G}^{S}(\theta) f(\theta) d \theta-I x^{F C .}
\end{aligned}
$$

The left hand side (LHS) of the above inequality denotes the equilibrium value of the social welfare under less-than-full compensation with restitution. Under full compensation the government can realize any of the projects whenever it is of interest to the government. Therefore, the social welfare is given by $\int_{\tilde{\Theta}^{G}\left(\mathbf{x}^{F C}\right)} \operatorname{Iv}\left(x^{F C}\right) f(\theta) d \theta+$

\footnotetext{
${ }^{54}$ Recall, $\mathbb{P}^{S+}(\theta, \mathbf{x}) \neq \emptyset$ implies $\mathbb{P}^{G+}(\theta, \mathbf{x}) \cap \mathbb{P}^{S+}(\theta, \mathbf{x}) \neq \emptyset$.

${ }^{55}$ The concavity assumption is not a necessary conditions for the claim to hold.
} 


$$
\begin{aligned}
& \int_{\Theta^{G}\left(\mathbf{x}^{F C}\right)} \beta_{G *}^{S}(\theta) f(\theta) d \theta-I x^{F C} \text {. Moreover, } \\
& \int_{\tilde{\Theta}^{S}\left(\mathbf{x}^{F C}\right)} I v\left(x^{F C}\right) f(\theta) d \theta+\int_{\Theta^{S}\left(\mathbf{x}^{F C}\right)} \beta_{S \cap G}^{S}(\theta) f(\theta) d \theta-I x^{F C} \geq \\
& \int_{\tilde{\Theta}^{G}\left(\mathbf{x}^{F C}\right)} I v\left(x^{F C}\right) f(\theta) d \theta+\int_{\Theta^{G}\left(\mathbf{x}^{F C}\right)} \beta_{G *}^{S}(\theta) f(\theta) d \theta-I x^{F C,},
\end{aligned}
$$

This inequality holds since the investment levels are the same on both sides. However, unlike on the RHS, the LHS admits a taking if and only if the project benefits are greater than the opportunity cost of the taking. So, we have

$$
\begin{aligned}
\int_{\tilde{\Theta}^{S}\left(\mathbf{x}^{\prime}\right)} I v\left(x^{\prime}\right) f(\theta) d \theta & +\int_{\Theta^{S}\left(\mathbf{x}^{\prime}\right)} \beta_{S \cap G}^{S}(\theta) f(\theta) d \theta-I x^{\prime}> \\
& \int_{\tilde{\Theta}^{G}\left(\mathbf{x}^{F C}\right)} I v\left(x^{F C}\right) f(\theta) d \theta+\int_{\Theta^{G}\left(\mathbf{x}^{F C}\right)} \beta_{S \cap G}^{S}(\theta) f(\theta) d \theta-I x^{F C .}
\end{aligned}
$$

A argument along the same lines can be made for Scenario 2.

Proof of Proposition 6: Let $c(\cdot)=c^{* *}$ be the compensation paid by the government to an owner if land is acquired. Assume that $c^{* *}<v\left(x^{*}\right)$, where $x^{*}$ is the first best efficient level of investment. Additionally, we assume that the cost of litigation, $c_{L}$, is such that $v\left(x^{*}\right)-c_{L}>c^{* *}$.

First, consider the government's decision at $t=2$. Assume that each owner has chosen to invest $x^{*}$ at $t=1$. Note that $\mathbb{P}^{S+}\left(\theta, \mathbf{x}^{*}\right) \neq \emptyset$ holds iff $\theta \in \Theta^{*}\left(\mathbf{x}^{*}\right)$. Therefore, $\theta \in \Theta^{*}\left(\mathbf{x}^{*}\right)$ implies that $\mathbb{P}^{G+}\left(\theta, \mathbf{x}^{*}\right) \cap \mathbb{P}^{S+}\left(\theta, \mathbf{x}^{*}\right) \neq \emptyset$, in view of the assumption that $\mathbb{P}^{G+}(\theta, \mathbf{x}) \cap \mathbb{P}^{S+}(\theta, \mathbf{x}) \neq \emptyset$ whenever $\mathbb{P}^{S+}(\theta, \mathbf{x}) \neq \emptyset$. Since the judiciary allows taking when $\theta \in \Theta^{*}\left(\mathbf{x}^{*}\right)$, it means that the government will always go for taking when $\theta \in \Theta^{*}\left(\mathbf{x}^{*}\right) .{ }^{56}$ On the other hand, if the government attempts a taking when $\theta \notin \Theta^{*}\left(x^{*}\right)$ then the every owner would have incentive to challenge such taking, since $v\left(x^{*}\right)-c_{L}>c^{* *}$. The judicial review would lead to stalling of such a taking decision. Therefore, the government's best response is to go for taking iff $\theta \in \Theta^{*}\left(x^{*}\right)$.

Next, consider an owners investment decision, assuming that at $t=2$ the government will engage in taking if and only $\theta \in \Theta^{*}\left(x^{*}\right)$. This means at $t=1$, an owner's optimization problem is:

$$
\max _{x}\left\{F\left(\hat{\theta}\left(x^{*}\right)\right) v(x)+\left(1-F\left(\hat{\theta}\left(x^{*}\right)\right)\right) c^{* *}-x\right\} .
$$

\footnotetext{
${ }^{56}$ When $\theta \in \Theta^{*}\left(x^{*}\right)$ the government will go for taking for its most favoured project belonging to the set $\mathbb{P}^{G+}\left(\theta, \mathbf{x}^{*}\right) \cap \mathbb{P}^{S+}\left(\theta, \mathbf{x}^{*}\right)$. Such a taking won't be stalled by judicial review, hence there is no incentive for the owners to challenge because litigation is expensive.
} 
Clearly $x^{*}$ is a unique payoff maximizing response by the each owner.

Moreover the equilibrium is sub-game perfect. To see this, assume that owners other than $i$ have opted for $x^{*}$. Now, consider the choice facing owner $i$. In view of the above note that at $t=2$, for any owner investing $x^{*}$ it is optimal to challenge the taking decision whenever $\theta \notin \Theta^{*}\left(x^{*}\right)$. So, the government cannot succeed in taking when $\theta \notin \Theta^{*}\left(x^{*}\right)$ as long as at least one owner has opted for $x^{*}$. On the other hand, the government will always go for taking when $\theta \in \Theta^{*}\left(\mathbf{x}^{*}\right)$. In particular, This means that when every other owner is choosing $x^{*}$, it would restrict the takings to the set $\theta \in \Theta^{*}\left(x^{*}\right)$ and hence $i^{\prime} s$ decision won't be pivotal; the probability of takings remains $F\left(\hat{\theta}\left(x^{*}\right)\right)$, regardless of the choice by owner $i$. Given that probability of taking is $F\left(\hat{\theta}\left(x^{*}\right)\right), x^{*}$ is a unique best response for owner $i$. We have already seen that when all owners choose investment level $x^{*}$, then government's best response is to go for takings iff $\theta \in \Theta^{*}\left(x^{*}\right)$. Thus the equilibrium is sub-game perfect.

Proof of Proposition 9: In case of the benevolent government, the taking decision and project choice at $\mathrm{t}=2$ is the same as in the case of the first best. Therefore, the probability of no-taking is given by $F(\hat{\theta}(\mathbf{x}))$, for any given profile of investments $\mathbf{x}$. So, for owner $i$, the optimization problem is as in (17). Therefore, it can be shown that under less than full compensation the vector of equilibrium investments choices made by the owners, say $\mathbf{x}^{\prime}(\gamma)$ is such that $\mathbf{x}^{*}<\mathbf{x}^{\prime}(\gamma)<\mathbf{x}^{F C}$. However, under full compensation, equilibrium vector of investments is $\mathbf{x}^{F C}$, as defined above.

Moreover, when the government is benevolent, for any given profile of investments, $\mathbf{x}$, the social welfare is given by:

$$
\int_{\underline{\theta}}^{\hat{\theta}(\mathbf{x})} \sum_{i=1}^{I} v\left(x_{i}\right) f(\theta) d \theta+\int_{\hat{\theta}(\mathbf{x})}^{\bar{\theta}} \beta^{S *}(\theta) f(\theta) d \theta-\sum_{i=1}^{I} x_{i} .
$$

That is, the social welfare is maximized when $\mathbf{x}=\mathbf{x}^{*}$. By assumption the social welfare is concave and $\mathbf{x}^{*}<\mathbf{x}^{\prime}(\gamma)<\mathbf{x}^{F C}$, so we have

$$
\begin{aligned}
\int_{\underline{\theta}}^{\hat{\theta}\left(\mathbf{x}^{\prime}\right)} \sum_{i=1}^{I} v\left(x_{i}=\right. & \left.x^{\prime}\right) f(\theta) d \theta+\int_{\hat{\theta}\left(\mathbf{x}^{\prime}\right)}^{\bar{\theta}} \beta^{S *}(\theta) f(\theta) d \theta-\sum_{i=1}^{I}\left[x_{i}=x^{\prime}\right]> \\
& \int_{\underline{\theta}}^{\hat{\theta}\left(\mathbf{x}^{F C}\right)} \sum_{i=1}^{I} v\left(x_{i}^{F C}\right) f(\theta) d \theta+\int_{\hat{\theta}\left(\mathbf{x}^{F C}\right)}^{\bar{\theta}} \beta^{S *}(\theta) f(\theta) d \theta-\sum_{i=1}^{I} x_{i}^{F C} .
\end{aligned}
$$




\section{References}

Amir, R. (2005). Supermodularity and complementarity in economics: An elementary survey. Southern Economic Journal, pages 636-660.

Bernd Schäfer, H. (2017). Taking Law from an Economic Perspective with Reference to German Law in Kim Iljoong, Lee Hojun and Somin Ilya (eds.) Eminent Domain: A Comparative Perspective pp 8-37. Cambridge University Press.

Blume, L. and Rubinfeld, D. L. (1984). Compensation for takings: an economic analysis. California Law Review, 72(4):569-628.

Blume, L., Rubinfeld, D. L., and Shapiro, P. (1984). The taking of land: When should compensation be paid ? The Quarterly Journal of Economics, 99(1):7192.

Bohn, H. and Deacon, R. T. (2000). Ownership risk, investment, and the use of natural resources. American Economic Review, pages 526-549.

Brennan, T. J. and Boyd, J. (2006). Political economy and the efficiency of compensation for takings. Contemporary Economic Policy, 24(1):188-202.

Burrows, P. (1991). Compensation for compulsory acquisition. Land Economics, 67(1):49-63.

Calabresi, G. and Melamed, A. D. (1972). Property rules, liability rules, and inalienability: one view of the cathedral. Harvard Law Review, pages 1089-1128.

Chang, Y.-c. (2009). Empire building and fiscal illusion ? an empirical study of government official behaviors in takings. Journal of Empirical Legal Studies, 6(3):541-584.

Chang, Y.-c. (2012). Economic value or fair market value: What form of takings compensation is efficient? Supreme Court Economic Review, 20(1):35-88.

Chang, Y.-c. (2013). Private Property and Takings Compensation: Theoretical Framework and Empirical Analysis. Edward Elgar Publishing.

Chang, Y.-c. (2017). Eminent Domain Law in Taiwan: New Law, Old Practice? in Kim Iljoong, Lee Hojun and Somin Ilya (eds.) Eminent Domain: A Comparative Perspective, pp 636-660. Cambridge University Press.

Claeys, E. R. (2003). Takings, regulations, and natural property rights. Cornell Law Review, 88(6):1549-1671. 
Cohen, D. S. (1990). Regulating regulators: The legal environment of the state. The University of Toronto Law Journal, 40(2):213-270.

Cohen, L. (1991). Holdouts and free riders. The Journal of Legal Studies, 20(2):351362.

Dagan, H. (2000). Just compensation, incentives, and social meanings. Michigan Law Review, 99(1):134-156.

Dana, D. A. and Merrill, T. W. (2002). Property: Takings. New York: Foundation Press.

Dari-Mattiacci, G., Garoupa, N. M., and Gomez-Pomar, F. (2010). State liability. European Review of Private Law, 18(4).

Ellickson, R. and Been, V. (2005). Land Use Controls, Cases and Materials. New York: Aspen Publishers, 3rd edition.

Epstein, R. A. (1985). Takings: Private property and the power of eminent domain. Cambridge, MA: Harvard University Press.

Epstein, R. A. (1995). Bargaining with the State. Princeton, NJ: Princeton University Press.

Epstein, R. A. (2008). Supreme Neglect: How to Revive Constitutional Protection for Private Property, volume 4. Oxford University Press.

Epstein, R. A. (2012). The takings clause and partial interests in land: On sharp boundaries and continuous distributions. Brooklyn Law Review, 78:589.

Farber, D. A. (1992). Economic analysis and just compensation. International Review of Law and Economics, 12(2):125-138.

Fischel, W. A. (1995). Regulatory takings: Law, economics, and politics. Harvard University Press.

Fischel, W. A. (2015). The coase theorem, land use entitlements, and rational government. Zoning rules!: the economics of land use regulation, Eds. William A Fischel, pages 219-260.

Fischel, W. A. and Shapiro, P. (1989). A constitutional choice model of compensation for takings. International Review of Law and Economics, 9(2):115-128. 
Fon, V. and Schäfer, H.-B. (2007). State liability for wrongful conviction: Incentive effects on crime levels. Journal of Institutional and Theoretical Economics, 163(2):269-284.

Garnett, N. S. (2006). The neglected political economy of eminent domain. Michigan Law Review, pages 101-150.

Ghatak, M. and Mookherjee, D. (2014). Land acquisition for industrialization and compensation of displaced farmers. Journal of Development Economics, 110:303 -312 .

Giammarino, R. and Nosal, E. (2005). Loggers versus campers: Compensation for the taking of property rights. Journal of Law, Economics and Organization, 21(1):136-152.

Glaeser, E. L., Ponzetto, G. A., and Shleifer, A. (2016). Securing property rights. National Bureau of Economic Research, Working Paper No 22701.

Göller, D. and Hewer, M. (2014). Economic analysis of taking rules: The bilateral investment case. Journal of Institutional and Theoretical Economics, 170(3):520536.

Herber, F.-R. (2015). On the imortance of expropriation in the roman empire and in modern europe. European Scientific Journal, 11(1).

Hermalin, B. E. (1995). An economic analysis of takings. Journal of Law Economics \& Organization, pages 64-86.

Innes, R. (1997). Takings, compensation, and equal treatment for owners of developed and undeveloped property. The Journal of Law and Economics, 40(2):403432 .

Innes, R. (2000). The economics of takings and compensation when land and its public use value are in private hands. Land Economics, pages 195-212.

Innes, R. and Frisvold, G. (2009). The economics of endangered species. Annual Review of Resoure Economics, 1(1):485-512.

Kaplow, L. (1986). An economic analysis of legal transitions. Harvard Law Review, pages 509-617.

Kaplow, L. (1992). Government relief for risk associated with government action. Scandinavian Journal of Economics, 94:525-41. 
Klerman, D. (2017). Takings, fiscal illusion, and the median voter. Journal of Institutional and Theoretical Economics, 173(1):71-76.

Leisner, W. (2010). Eigentum. Handbuch des Staatsrechts, 8.

Levinson, D. J. (2000). Making government pay: Markets, politics, and the allocation of constitutional costs. The University of Chicago Law Review, pages $345-420$.

Levinson, D. J. (2008). Empire-building government in constitutional law. Harvard Law Review, 118:915.

Merrill, T. W. (2002). Incomplete compensation for takings. New York University Environmental Law Review, 11:110.

Miceli, T. J. (1991). Compensation for the taking of land under eminent domain. Journal of Institutional and Theoretical Economics, pages 354-363.

Miceli, T. J. (2008). Public goods, taxes, and takings. International Review of Law and Economics, 28(4):287-293.

Miceli, T. J. (2011). The economic theory of eminent domain : private property, public use. Cambridge Books.

Miceli, T. J. and Segerson, K. (1994). Regulatory takings: When should compensation be paid? The Journal of Legal Studies, 23(2):749-776.

Miceli, T. J. and Segerson, K. (2012). Land assembly and the holdout problem under sequential bargaining. American Law and Economics Review, 14(2):372-390.

Miceli, T. J., Segerson, K., et al. (2007). The economics of eminent domain: private property, public use, and just compensation. Foundations and Trends® in Microeconomics, 3(4):275-329.

Michelman, F. I. (1967). Property, utility, and fairness: Comments on the ethical foundations of just compensation law. Harvard Law Review, pages 1165-1258.

Milgrom, P. and Roberts, J. (1990). Rationalizability, learning, and equilibrium in games with strategic complementarities. Econometrica, pages 1255-1277.

Mueller, D. C. (1989). Public choice 11. Cambridge: Cambridge.

Munch, P. (1976). An economic analysis of eminent domain. Journal of Political Economy, 84(3):473-497. 
Niemann, P. and Shapiro, P. (2008). Efficiency and fairness: Compensation for takings. International Review of Law and Economics, 28(3):157-165.

Niemann, P. and Shapiro, P. (2010). Compensation for taking when both equity and efficiency matter. In Property Rights (Eds. Benson B.L.), pages 55-76. Palgrave Macmillan, New York.

Nosal, E. (2001). The taking of land: market value compensation should be paid. Journal of Public Economics, 82(3):431-443.

Pecorino, P. (2011). Optimal compensation for regulatory takings. American Law and Economics Review, 13(1):269-289.

Pecorino, P. (2013). Compensation for regulatory takings with a redistributive government. Southern Economic Journal, 80(2):488-501.

Polasky, S. and Doremus, H. (1998). When the truth hurts: endangered species policy on private land with imperfect information. Journal of Environmental Economics and Management, 35(1):22-47.

Posner, R. A. (2003). Economic Analysis of Law. New York: Aspen Publishers, 6th edition.

Posner, R. A. (2014). Economic analysis of law. Wolters Kluwer Law \& Business, 9th edition.

Ramesh, J. and Khan, M. A. (2015). Legislating for justice: The making of the 2013 land acquisition law. Oxford University Press, New Delhi.

Riddiough, T. J. (1997). The economic consequences of regulatory taking risk on land value and development activity. Journal of Urban Economics, 41(1):56-77.

Sabahi, B. and Birch, N. J. (2010). Comparative compensation. International Investment Law and Comparative Public Law (Oxford University Press 2010: published at Oxford Scholarship Online, 2011) , pp 2-31, pages Eds. Schill, Stephan W.

Schäfer, H.-B. (2017). Taking law from an economic perspective with reference to german law. Eminent Domain: A Comparative Perspective, Eds. Kim, Iljoong and Lee, Hojun and Somin, Ilya, Cambridge University Press(pp):8-37.

Schweizer, U. (2017). Efficient compensation: Lessons from civil liability. Journal of Institutional and Theoretical Economics, 173(1):54-70.

Serkin, C. (2004). The meaning of value: Assessing just compensation for regulatory takings. Northwestern University Law Review, 99:677. 
Shavell, S. (2010). Eminent domain versus government purchase of land given imperfect information about owners valuations. The Journal of Law and Economics, $53(1): 1-27$.

Singh, R. (2012). Inefficiency and abuse of compulsory land acquisition: an enquiry into the way forward. Economic and Political Weekly, 47(19):46-53.

Somin, I. (2012). What if kelo v.s. city of new london had gone the other way? Indian Law Review, 45(1):21-39.

Somin, I. (2015). The Grasping Hand : kelo V. City of New London and the Limits of Eminent Domain. University of Chicago Press.

Strange, W. C. (1995). Information, holdouts, and land assembly. Journal of Urban Economics, 38(3):317-332.

Tideman, T. N. and Plassmann, F. (2005). Fair and efficient compensation for taking property under uncertainty. Journal of Public Economic Theory, 7(3):471-495.

Treanor, W. M. (1985). The origins and original significance of the just compensation clause of the fifth amendment. The Yale Law Journal, 94(3):694-716.

Trefzger, J. W. and Colwell, P. F. (1996). Investor efficiency in the face of takings. The Journal of Real Estate Finance and Economics, 12(1):23-35.

Yandle, B. (1995). Land rights: the 1990's property rights rebellion. Rowman \& Littlefield Publishing Inc. 